Argonne

\title{
Initial development and verification of a primary load design method based on elastic-perfectly plastic analysis
}

Applied Materials Division 


\section{About Argonne National Laboratory}

Argonne is a U.S. Department of Energy laboratory managed by UChicago Argonne, LLC under contract DE-AC02-06CH11357. The Laboratory's main facility is outside Chicago, at 9700 South Cass Avenue, Argonne, Illinois 60439. For information about Argonne and its pioneering science and technology programs, see www.anl.gov.

\section{DOCUMENT AVAILABILITY}

Online Access: U.S. Department of Energy (DOE) reports produced after 1991 and a growing number of pre-1991 documents are available free via DOE's SciTech Connect (http://www.osti.gov/scitech/)

\section{Reports not in digital format may be purchased by the public from the} National Technical Information Service (NTIS):

U.S. Department of Commerce

National Technical Information Ser-

vice 5301 Shawnee Rd

Alexandria, VA 22312

www.ntis.gov

Phone: (800) 553-NTIS (6847) or (703) 605-6000

Fax: (703) 605-6900

Email: orders@ntis.gov

Reports not in digital format are available to DOE and DOE contractors from the Office of Scientific and Technical Information (OSTI):

U.S. Department of Energy

Office of Scientific and Technical Information

P.O. Box 62

Oak Ridge, TN 37831-0062

www.osti.gov

Phone: (865) 576-8401

Fax: (865) 576-5728

Email: reports@osti.gov

\section{Disclaimer}

This report was prepared as an account of work sponsored by an agency of the United States Government. Neither the United States Government nor any agency thereof, nor UChicago Argonne, LLC, nor any of their employees or officers, makes any warranty, express or implied, or assumes any legal liability or responsibility for the accuracy, completeness, or usefulness of any information, apparatus, product, or process disclosed, or represents that its use would not infringe privately owned rights. Reference herein to any specific commercial product, process, or service by trade name, trademark, manufacturer, or otherwise, does not necessarily constitute or imply its endorsement, recommendation, or favoring by the United States Government or any agency thereof. The views and opinions of document authors expressed herein do not necessarily state or reflect those of the United States Government or any agency thereof, Argonne National Laboratory, or UChicago Argonne, LLC. 


\section{Initial development and verification of a primary load design method based on elastic-perfectly plastic analysis}

Applied Materials Division

Argonne National Laboratory

July 2020

Prepared by

Mark C. Messner

T.-L. Sham 



\section{ABSTRACT}

This report describes a new primary load design method to supplement the current design-byelastic-analysis rules in Section III, Division 5, Subsection HB, Subpart B of the ASME Boiler and Pressure Vessel Code, covering the design and construction of Class A high temperature nuclear structural components. The main objectives for the new design method are to provide a procedure that can be applied to components with complicated geometries and to simplify the primary load design process by providing rules more compatible with modern finite element analysis. The report includes a complete set of design rules, presented as a draft ASME Code Case, as well as a commentary on the rules and a set of verification problems. The verification design problems demonstrate the new primary load design rules produce safe, efficient components when compared to the current Division 5 approach, while greatly simplifying the design analysis process. 



\section{TABLE OF CONTENTS}

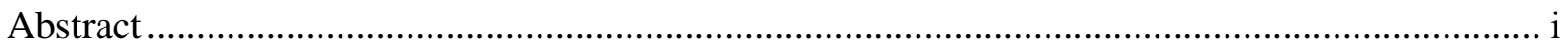

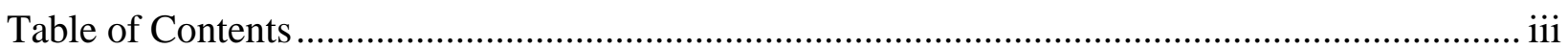

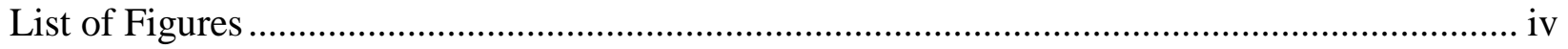

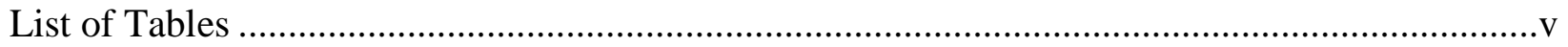

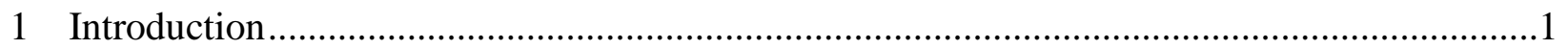

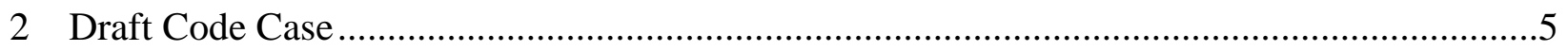

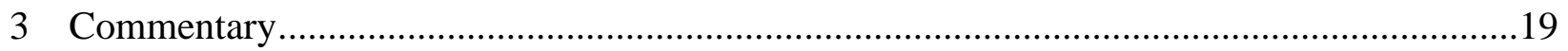

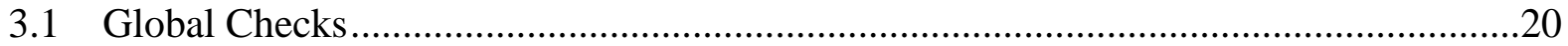

3.2 An Alternative Approach: Equilibrium Field Scaling ..............................................22

L.3 Local Service Check .........................................................................................24

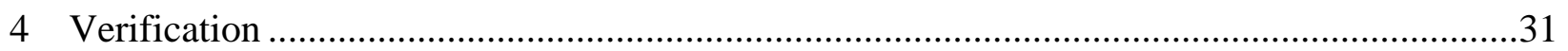

4.1 Cylindrical Thin-walled Pressure Vessel................................................................31

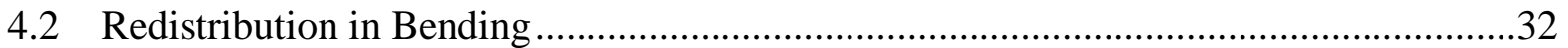

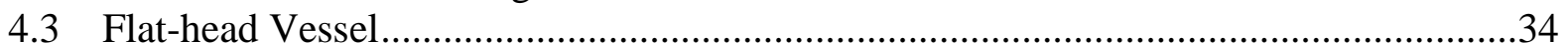

4.4 Section I/Section VIII Grade 91 Reference Problems .................................................36

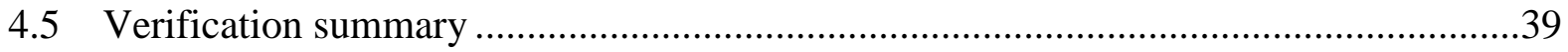

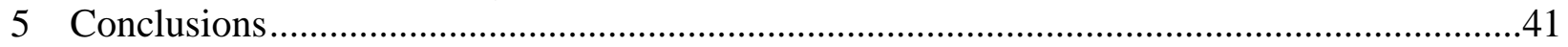

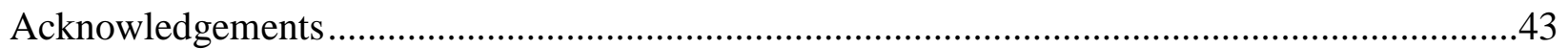

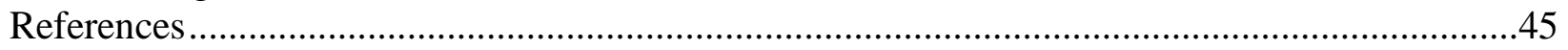




\section{LIST OF FIGURES}

Figure 4.1. Simple bending example. The dotted lines illustrate an elastic and fully-plastic stress distribution 32

Figure 4.2. Flat head vessel geometry and service load definition. ....................................................... 34 Figure 4.3. Maximum allowable pressures for the flat head vessel for various design methods and design

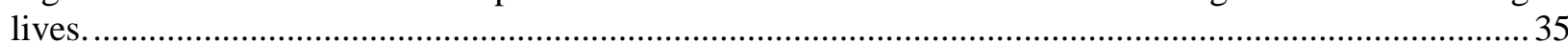
Figure 4.4. Collection of commercial Section I/VIII sample problems used to evaluate the new design

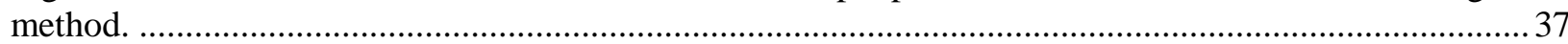
Figure 4.5. Comparison between the current HBB primary load design rules and the new proposed EPP method for the Section I/VIII reference problems. 


\section{LIST OF TABLES}

Table 4.1. Maximum pressure data for the flat head vessel comparison. .................................................. 35

Table 4.2. Maximum allowable pressures for the Section I/VIII sample problems................................. 38 



\section{Introduction}

This report describes the development of a new primary load design method for high temperature nuclear structural components based on elastic perfectly-plastic (EPP) and simplified inelastic analysis. The new design method aims to overcome limitations of the current ASME Section III, Division 5 primary load design rules, in particular aiming to provide a streamlined design method for components with complicated geometries. The report presents the design rules as a draft nuclear Code Case, to be presented and balloted by the cognizant ASME Boiler \& Pressure Vessel Code Committees. The rules are an alternative approach for primary load design to the current rules in Section III, Division 5, Subsection HB, Subpart B (HBB) of the Boiler Code, covering the design and construction of Class A high temperature reactor components.

Subsection HB, Subpart B covers the design of Class A pressure boundary components. The rules require the designer to assess five design criteria:

1. Primary load design, covering plastic collapse and creep failure under steady state conditions.

2. Time-independent buckling.

3. Time-dependent (creep) buckling.

4. Strain accumulation (ratcheting)

5. Creep-fatigue.

In the design process described in HBB, primary load design occurs first and is often used to establish the basic geometric design of a component. The current primary load design rules use a design-by-elastic analysis approach. This requires the designer to complete an elastic stress analysis of the component and then classify the stresses as primary, secondary, or peak. This stress classification process is a manual, engineering-judgement based correction to a major defect of applying an elastic stress analysis to a component that operates in the creep range: the elastic analysis does not account for stress redistribution caused by creep or plasticity. This stress redistribution reduces the stresses in the component and increases the component rupture life, versus a hypothetical elastic stress distribution. The current design-byelastic-analysis rules partially account for this redistribution through the use of section factors, but cannot fully account for structural redistribution in components with redundant load paths.

Stress classification is ultimately up to the engineering judgement of the designer and so it remains one of the largest areas of uncertainty in the current Code rules. Stress classification methods are well-established for standard, axisymmetric component geometries like cylindrical vessels, standard vessel heads, and nozzles. Stress classification is much more difficult, bordering on impossible, for complicated components with 3D geometries. A core block in a 
microreactor is an example of such a component, meaning the development of new primary load design rules is of critical importance for these types of reactor concepts.

Additionally, the current design-by-elastic-analysis rules are difficult to implement in modern finite element analysis (FEA) frameworks. The process of stress classification and linearization - required to resolve the stresses into membrane and bending components - is not easily automated in a FEA framework. While methods based on Stress Classification Lines (SCLs) do exist they still represent an additional complication in a design analysis. Overall, the current HBB primary load design rules are seen as overcomplicated, particularly for engineers trained to use FEA tools for design by analysis.

This report describes a new set of proposed primary load design rules. The objectives in developing these rules were:

1. Eliminate stress classification.

2. Fully account for the beneficial effects of stress redistribution due to creep and plasticity at elevated temperatures.

3. Develop design rules that can be easily executed using modern FEA and post-processing tools.

4. Maintain compatibility with the current Section III, Division 5 allowable stresses and material data.

5. Produce design criteria that result in designs comparable to the current design-by-elasticanalysis rules.

6. Allow for more optimal primary load designs, compared to the current approach, while maintaining component design margins.

The final two criteria are to decouple the design analysis procedures from any change in the allowable stress criteria, which is a more fundamental alteration that would require additional validation. Accepting criteria \#4 and \#5 means the new method can be verified by comparing it to results from the current HBB rules. These criteria will also simplify the process of adopting the design rules through the relevant ASME Code Committees.

The new primary load design rules described here combine two analysis techniques:

- Elastic perfectly-plastic (EPP) analysis: design analysis using an EPP constitutive model and a specially-defined pseudo yield stress. This analysis bounds the actual stress redistribution in the component.

- Simplified inelastic analysis: design analysis using an elastic-creep constitutive model. This analysis more directly represents the real redistribution of stress in the component.

EPP analysis has already been adopted by ASME to provided simplified methods for meeting the Code ratcheting (Code Case N-861 [1]) and creep-fatigue (Code Case N-862 [2]) criteria. The new method, using a bounding pseudo yield stress, can be applied to check components against the current Section III, Division 5 allowable stresses without the need for stress classification and linearization. As described in more detail in Chapter 3, a second design check 
based on simplified inelastic analysis is required to provide a limit on the amount of stress redistribution that can actually occur in a component. This check is a supplement to the EPP check on the HBB Design and Service allowable stresses.

Chapter 2 presents the new design rules in the form of a draft ASME Code Case. Chapter 3 is a commentary describing the process of developing the new rules and explaining the various decisions on analysis methods, allowable stresses, and supplemental design checks that went into the development of the new primary load design process. Chapter 4 then verifies the method produces comparable designs to the current HBB rules. This chapter includes a comparison to a set of actual, in-service Section I/Section VIII non-nuclear components which demonstrates the adequacy of the new design approach. Finally, Chapter 5 summarizes the conclusions developed here and describes the process of adopting the new design rules as a nuclear Code Case. 



\section{Draft Code Case}

The following chapter provides the new design method in the form of a draft nuclear Code Case. Tables and figures are deliberately numbered as internal to the Code Case language and not included in the global table and figure numbering scheme nor in the list of tables and figures for this report.

\section{Primary Load Analysis for Division 5 Class A Components at Elevated Temperature Service Using Elastic-Perfectly Plastic and Simplified Inelastic Analyses Section III, Division 5}

Inquiry:

What alternate rules can be used to satisfy the primary load limits for Class A components contained in Section III, Division 5, Subsection HB, Subpart B, HBB-3222, HBB-3223, and HBB-3224?

Reply:

The following rules may be used to satisfy the primary load limits for Class A components contained in Section III, Division 5, Subsection HB, Subpart B, HBB-3222, HBB-3223, and HBB-3224.

The terms and requirements of Mandatory Appendix I shall be used for this code case.

\section{Design Limits.}

The provisions of this section replace the requirements of HBB-3222.1 and HBB-3221(a) and HBB3221(b). The requirements of HBB-3222.1 related to buckling strength remain applicable. HBB-3222.2 is not applicable when implementing this code case.

The design methodology employed for the analysis of the Design Loadings is based on the application of limit load analysis as described in Mandatory Appendix I.

The following assessment procedure is used to determine the acceptability of a component subject to Design Loadings.

STEP 1. - Develop a numerical model of the component including all relevant geometric characteristics. The model used for the analysis shall be selected to accurately represent the welded component geometry, boundary conditions, and applied loads. The model for Design Loadings evaluation need not be accurate for small details, such as small holes, fillets, corner radii, and other stress risers, but should otherwise correspond to commonly accepted practice. The local temperature for the numerical model shall correspond to the Design Temperature. As such, this analysis will not include thermal stresses - the model is isothermal.

STEP 2 - The specified design parameters for the Design Loadings category, the Design Temperature and the Design Pressure, shall be defined per HBB-3113.1. The concept of specified load duration is not used. The Design Limits analysis per this Code Case does not include any Design Mechanical Loads or selfweight.

STEP 3 - Select the pseudo yield stress. The pseudo yield stress for the limit load analysis in STEP 4 below shall be equal to $\sqrt{3 / 4} S_{o}$, with $S_{o}$ as defined in HBB-3221(b). 
STEP 4 - Perform an EPP analysis per Mandatory Appendix I-6 for the specified design parameters defined in STEP 2. Note that if the Design Loadings result in compressive stress fields within the component, buckling may occur and should be evaluated per HBB-3250.

STEP 5 - If the EPP analysis in STEP 4 does not pass the criteria in Mandatory Appendix I-6 the component configuration (i.e., thickness) shall be modified or the Design Loadings reduced and STEPS 1 to 5 repeated. Alternatively, the structure may be deemed adequate for the Design Limits check if it fulfills the criteria in STEP 6.

STEP 6 - Modification of component configuration or reduction of the Design Loadings in accordance with STEP 5 is not required if it can be shown that the component meets the thickness requirements for Design Loadings in the design-by-rule provisions in HCB-3300, HCB-3400, HCB-3500 and HCB-3600, using an allowable stress, $S_{o}$, as defined in HBB-3221(b).

\section{Service Level Limits.}

The provisions of this section replace the requirements of HBB-3223 and HBB-3224. The following assessment procedure is used to determine the acceptability of a component subject to Level A, B and C service loadings. The acceptability of a component under a sustained load system shall be demonstrated through a Global Check that is intended to address the satisfaction of allowable stress limits for the global response, and a Local Check that is intended to address the onset of local creep-rupture under sustained loads. The Global Check is based on an EPP analysis methodology and the Local Check is based on a simplified inelastic analysis methodology using an elastic-creep material model.

If the service level loadings result in compressive stress fields within the component, buckling may occur and should be evaluated per HBB-3250. The load systems definition in Paragraph 2.1 and the numerical model for analysis in Paragraph 2.2 are the same for the Global Check and Local Check.

\subsection{Load Cases}

Define all applicable specified load systems, load durations and steady state temperatures for each load case per HBB-3113.2, Service Loadings for Levels A, B and C, as shown in Table 1. Here the load case $L$ is defined by corresponding pressures, $p$, self-weight loads, $w$, mechanical loads, $h$, and design temperature distribution $T_{\text {design }}(x)$. The design temperature distribution for this Code Case is the actual steady state temperature distribution, $T(x)$, rather than a zonal Specified Temperature per HBB-3112.2, except when using the alternate Global Check criteria described in Nonmandatory Appendix A. Each load case has an associated duration, $t$, and Service Level A, B or C.

Table 1.

\begin{tabular}{|c|c|c|c|}
\hline Specified loading system & $\begin{array}{c}\text { Specified load } \\
\text { duration }\end{array}$ & $\begin{array}{c}\text { Specified steady state } \\
\text { temperature distribution }\end{array}$ & $\begin{array}{c}\text { Service } \\
\text { Level }\end{array}$ \\
\hline$L_{\text {design }}=\left\{p_{\text {design }}, w_{\text {designs }}, h_{\text {design }}\right\}$ & $t_{\text {design }}$ & $T_{\text {design }}(x)$ & $A, B$ or $C$ \\
\hline
\end{tabular}

\subsection{Numerical Model for Analysis of Service Loadings}

A numerical model of the component including all relevant geometric characteristics shall be developed. The model used for the analysis shall be selected to accurately represent the welded component geometry, boundary conditions, and applied loads. The model for evaluation must also be accurate for small details, 
such as small holes, fillets, corner radii, and other stress risers. Weldment details must be modeled as described in Paragraph 2.2.1 of this Case. The local temperature shall correspond to the steady state operating condition for the applicable Service Loading.

\subsubsection{Weld Region Model Boundaries}

Weld regions must be identified and resolved in the numerical model.

The weld shown in Figure 1 represents a general full penetration butt weld in a shell. Other weld configurations are needed for construction of an elevated temperature component in accordance with Section III, Division 5, Subsection HB, Subpart B. Paragraph HBB-4200 refers to various Section III, Division 1, Article NB-4000 paragraphs for weld configurations and requirements. These Subsection NB weld configurations are represented by the shaded region.

Figure 1 shows a full-penetration butt weld as an example. As shown, $w_{1}$ and $w_{2}$, as needed to define the weld region for use of this Case, are approximations consistent with the specified weld configuration and parameters. The specified weld region must include applicable stress concentrations in accordance with the requirements for analysis of geometry of Section III, Division 5, HBB-T-1714.

\section{Figure 1}

\section{Weld Region Model Boundaries}

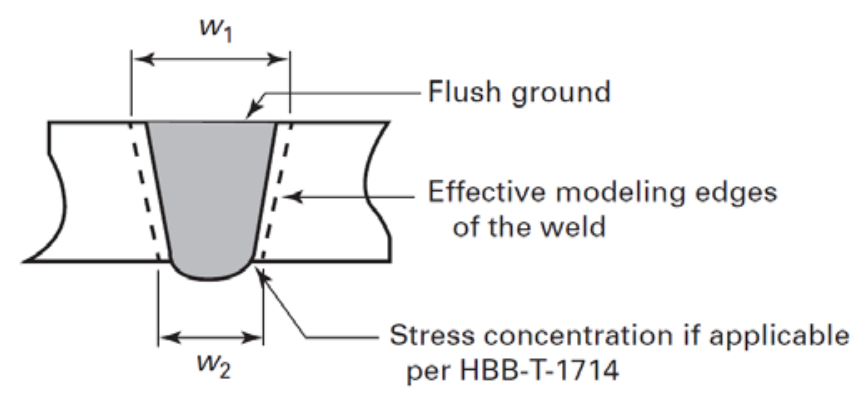

\subsection{Acceptance Assessment.}

The specified load systems for all the load cases shall be acceptable when both Global and Local Checks are satisfied.

\subsubsection{Global Check}

The component must pass the criteria listed in 2.3.1.1 or 2.3.1.2 to pass the Global Service Load Check.

2.3.1.1. Global Check - Base Procedure.

STEP 1 - EPP analysis.

For each load case $i$ :

(i) Select the pseudo yield stress $Y_{\text {global }}^{i}(x)$ at each point $x$ of the numerical model according to Mandatory Appendix I-5 accounting for the Service Level of the load case and whether $x$ is within the base metal or the weldment. The temperature at $x$ shall be the specified steady state 
temperature $T_{\text {design }}^{i}(x)$ and the time duration in the expression for the pseudo yield stress, $t$, shall be set to some trial time $t_{\text {trial }}^{i}$ greater than or equal to the specified load duration, $t_{\text {design }}^{i}$, i.e., $t_{\text {trial }}^{i} \geq t_{\text {design. }}^{i}$.

(ii) Perform an EPP analysis to determine if the finite element solution for the specified loading system $L_{\text {design }}^{i}$ converges per Mandatory Appendix I-6.

(iii) If $L_{\text {design }}^{i}$ passes the EPP analysis per Mandatory Appendix I-6 with the trial time $t_{\text {trial }}^{i}$ go to STEP 2. If $L_{\text {design }}^{i}$ does not pass decrease the trial time $t_{\text {trial }}^{i}$, which increases the pseudo yield stress, and repeat STEP 1 . If $L_{\text {design }}^{i}$ does not converge for any trial time $t_{\text {trial }}^{i} \geq t_{\text {design }}^{i}$ then the loads in $L_{\text {design }}^{i}$ or the component geometry must be altered.

STEP 2 - Cumulative Load Case Assessment

Calculate the use-fraction $\sum_{i} \frac{t_{\text {design }}^{i}}{t_{\text {trial }}^{i}}$. If the acceptance criteria

$$
\sum_{i} \frac{t_{\text {design }}^{i}}{t_{\text {trial }}^{i}} \leq 1
$$

is met the structure passes the individual load case assessment criteria of HBB-3223 and HBB-3224 and the use-fraction summation requirements of HBB-3224, proceed to the Local Check. If not go to STEP 3.

STEP 3 - Trial Time Optimization

Increase the trial time $t_{\text {trial }}^{i}$ for one or more load cases, which decreases the pseudo yield, and repeat STEPS 1-3. STEP 3 may be repeated until the times $t_{\text {opt }}^{i}$ are found for each load case $L_{\text {design }}^{i}$ where $t_{\text {opt }}^{i}$ is the time at which for any $t_{\text {trial }}^{i}>t_{\text {opt }}^{i}$ the load case $L_{\text {design }}^{i}$ fails to converge, i.e. the largest value of the trial time for which the loads $L_{\text {design }}^{i}$ do not exceed the limit load. If the times $t_{\text {opt }}^{i}$ are found for each load case and the use fraction criteria in STEP 2 is still not met using trial times $t_{\text {trial }}^{i}=t_{o p t}^{i}$ then either the loads or component geometry must be altered.

\subsubsection{Global Check - Alternate Procedure.}

Alternatively the designer may use the procedure described in Nonmandatory Appendix A if the component meets the criteria described in that Appendix.

\subsection{2 - Local Check by Simplified Inelastic Analysis.}

STEP - 1. Simplified inelastic analysis.

(i) For each load case $i$ :

(a) The material model for the numerical model of Paragraph 2.2 shall be based on a simplified inelastic model according to Mandatory Appendix I-8.

(b) The temperature distribution for the numerical model of Paragraph 2.2 shall be the specified steady state temperature $T_{\text {design }}^{i}(x)$ for the load case.

(c) Perform a simplified inelastic analysis per Mandatory Appendix I-9 using the numerical model of Paragraph 2.2 above. The numerical model is subject to the specified load system $L_{\text {design }}^{i}$ for a duration equal to the specified load duration $t_{\text {design }}^{i}$. 
(d) Calculate the cumulative creep damage over the specified load duration for each point $x$ in the numerical model:

(1) Determine the time history of the maximum principal stress $\sigma_{1}^{i}(x, t)$ and the von Mises effective stress $\sigma_{v}^{i}(x, t)$ from the stresses of the simplified inelastic analysis in step (c).

(2) Determine the cumulative creep damage $D_{i}^{c}(x)$ by following the steps in Mandatory Appendix I-10.

(i) Calculate the total cumulative creep damage for each point $x$ by summing the contributions from all load cases:

$$
D_{c}(x)=\sum_{i} D_{c}^{i}(x)
$$

(ii) Assessment. If the condition $D_{c} \leq 1$ is met for all the points in the numerical model the Local Check is satisfied and the specified load systems for all the load cases are acceptable.

(iii) Otherwise, the component configuration (for example, thickness) or the loading conditions shall be modified. The Global check of Paragraph 2.3.1 and the Local check of Paragraph 2.3.2 shall be repeated using the modified conditions until all the acceptability criteria are satisfied. 


\section{MANDATORY APPENDIX I TERMS AND REQUIREMENTS}

I-1. Load System, $L$. A load system consisting of body forces and surface tractions including:

(1) pressure, $p$;

(2) weight, $w$;

(3) mechanical (i.e. nozzle) loads, $h$.

It is symbolically denoted as

$$
L \equiv\{p, w, h\}
$$

The specified loads correspond to the full set of loading conditions for the Design Load or the Service Load under consideration. This Code Case works with factored loads based on these specified loads, as described in I-6.

I-2. Specified Steady State Temperature Field for Global Check, $T_{\text {design }}(x)$. The temperature distribution determined from a steady state thermal analysis based on specified thermal boundary conditions of steady state operating condition for the applicable Service Loading.

I-3. Specified Load Duration, $t_{\text {design }}$. The time duration where the specified load system $L_{\text {design }}$ is applied.

I-4. Pseudo yield stress for Global Service check, $Y_{\text {global }}(x)$. The pseudo yield stress $Y_{\text {global }}(x)$ for the global check of service loading at a point $x$ shall be defined for different materials and service levels per Table I-4, using the specified steady state temperature $T_{\text {design }}(x)$ and a time duration $t$. The allowable stress $S_{m}$, the allowable stress $S_{t}$, and the expected minimum stress-to-rupture strength $S_{r}$ in Table I-4 are the tabulated values for the base metal as defined in HBB-3221(b)(1) and $R$ is the stress rupture factor for the weldment as defined in HBB-3221(b)(2).

As described in HBB-2160(d), it may be necessary to adjust the values of $S_{m}$ to account for the effects of long-time service at elevated temperature. 
Table I-4. Definition of the pseudo yield stress $Y_{\text {global }}(x)$ for global check of service loading at a point $x$ for a time duration $t$ that depends on the method of assessment.

\begin{tabular}{|l|l|c|}
\hline Material & $\begin{array}{l}\text { Service } \\
\text { Level }\end{array}$ & Pseudo Yield Stress $Y_{\text {global }}(x)$ for Global Service Load Check \\
\hline $\begin{array}{l}\text { Base } \\
\text { metal }\end{array}$ & $A, B$ & $\sqrt{3 / 4} \times S_{m t}\left(T_{\text {design }}(x), t\right)$ \\
\hline $\begin{array}{l}\text { Base } \\
\text { metal }\end{array}$ & $C$ & Lesser of $\left\{\begin{array}{c}\sqrt{3 / 4} \times 1.2 \times S_{m}\left(T_{\text {design }}(x)\right) \\
\sqrt{3 / 4} \times S_{t}\left(T_{\text {design }}(x), t\right)\end{array}\right.$ \\
\hline Weldment & $A, B$ & Lesser of $\left\{\begin{array}{c}0.8 \times R\left(T_{\text {design }}(x), t\right) \times S_{r}\left(T_{\text {design }}(x), t\right) \\
\sqrt{3 / 4} \times 0.8)\end{array}\right.$ \\
\hline Weldment & $C$ & Lesser of $\left\{\begin{array}{c}\sqrt{3 / 4} \times 1.2 \times S_{m}\left(T_{\text {design }}(x)\right) \\
\sqrt{3 / 4} \times S_{t}\left(T_{\text {design }}(x), t\right) \\
\sqrt{3 / 4} \times 0.8 \times R\left(T_{\text {design }}(x), t\right) \times S_{r}\left(T_{\text {design }}(x), t\right)\end{array}\right.$ \\
\hline
\end{tabular}

I-5. von Mises Stress, $\sigma_{v}$. A stress invariant based on deviatoric stress components and can be defined in terms of the principal stresses $\sigma_{1}, \sigma_{2}$ and $\sigma_{3}$, with $\sigma_{1}$ denoting the maximum principal stress, as

$$
\sigma_{v}=\sqrt{\frac{1}{2}\left[\left(\sigma_{1}-\sigma_{2}\right)^{2}+\left(\sigma_{2}-\sigma_{3}\right)^{2}+\left(\sigma_{3}-\sigma_{1}\right)^{2}\right]}
$$

I-6. EPP analysis. A finite element analysis for the loads $L$, the temperature distribution $T(x)$, and pseudo yield stress $Y(x)$ with the following characteristics:

(1) The strain-displacement relations are those of small displacement gradient theory.

(2) Isotropic linear elastic properties given in Section II, Part D.

(3) Thermal properties given in Section II, Part D.

(4) The material model is elastic, perfectly plastic with the pseudo yield stress $Y(x)$.

(5) The von Mises yield condition and the associated flow rule are used.

(6) The resulting stress field is in equilibrium with a prescribed body force field in the body and balances specified tractions on external surfaces, all in the undeformed configuration. These conditions are satisfied with respect to the approximation of the finite element method.

Using this analysis model the structure passes the EPP analysis check if:

1. Define a factored load system $L^{m}=\{m p, m w, m h\}$ where $m \leq 1$ is the load factor.

2. $\quad$ Start with a small value of the load factor $m$

a. Perform the EPP analysis using the numerical model, the pseudo yield stress, and the factored load system.

b. If the numerical analysis converges - that is the solution technique successfully finds a stress distribution that satisfies the small-deformation equilibrium and compatibility conditions and the von Mises flow rule - increase the load factor $m$ and repeat step (2) until:

i. The numerical analysis converges for a load factor $m=1$. This result means the EPP analysis converges successfully. 
ii. The numerical analysis fails to converge for a load factor $m \leq 1$. This result means the EPP analysis fails to converge successfully.

I-7. Minimum-Stress-to-Rupture for Local Check of Service Loading, $M(x, t)$. The rupture stress $M(x, t)$ for the local check at a point $x$ and time $t$ shall be defined for different materials per Table I-7, using the specified temperature field $T_{\text {design }}(x)$. The rupture stress for each material is the same for Service Level A, B or C. The values of the expected minimum stress-to-rupture strength $S_{r}$ in Table I-7 are the tabulated values for the base metal as defined in HBB-3221(b)(1) and $R$ is the stress rupture factor for the weldment as defined in HBB-3221(b)(2).

Table I-7. Minimum-stress-to-rupture at a point $x$ and time $t$ for the local check.

\begin{tabular}{|l|l|}
\hline Material & $\begin{array}{l}\text { Minimum-stress-to-rupture } M(x, t) \text { for the Local } \\
\text { Check of Service Loading }\end{array}$ \\
\hline Base metal & $S_{r}\left(T_{\text {design }}(x), t\right)$ \\
\hline Weldment & $R\left(T_{\text {design }}(x), t\right) \times S_{r}\left(T_{\text {design }}(x), t\right)$ \\
\hline
\end{tabular}

I-8. Simplified Inelastic Material Model. The material model to be used for the simplified inelastic analysis shall be an elastic-creep model using a $J_{2}$ (von Mises) flow theory for the creep part. Acceptable material models for each of the Section III, Division 5 Class A materials are provided below:

All the following models are defined in metric units with stress in MPa, time in hours, nominal strains $(\mathrm{mm} / \mathrm{mm}$ ), and temperature in Celsius. The models may be converted to U.S. customary units for design calculations. For all material models the constitutive equation takes the form:

$$
\dot{\boldsymbol{\sigma}}=\boldsymbol{C}:\left(\dot{\boldsymbol{\varepsilon}}-\dot{\boldsymbol{\varepsilon}}_{t}-\dot{\boldsymbol{\varepsilon}}_{\boldsymbol{c}}\right)
$$

with $\dot{\boldsymbol{\sigma}}$ the stress rate to be integrated to provide the stress/strain relation; $\boldsymbol{C}$ is the isotropic elasticity tensor defined by the temperature dependent value of Young's modulus given in Table TM of Section II, Part D (Metric) for the material and the Poisson's ratio for the material given in Table PRD of Section II, Part D (Metric) ${ }^{1}$; $\dot{\varepsilon}$ is total strain rate from the finite element analysis; $\dot{\boldsymbol{\varepsilon}}_{t}$ the rate of thermal strain given by

$$
\dot{\varepsilon}_{t}=\alpha \dot{T} \mathbf{I}
$$

with $\alpha$ the temperature-dependent instantaneous coefficient of thermal expansion given in Table TE of Section II, Part D (Metric) for the material, $\dot{T}$ the temperature rate from the finite element analysis, and $\mathbf{I}$ the identity tensor; and $\dot{\boldsymbol{\varepsilon}}_{\boldsymbol{c}}$ is the creep rate defined by

$$
\dot{\varepsilon}_{c}=\dot{\varepsilon}_{c}\left(\sigma_{v}, T\right) \frac{3 \operatorname{dev}(\boldsymbol{\sigma})}{2 \sigma_{v}}
$$

with $\dot{\varepsilon}_{c}\left(\sigma_{v}, T\right)$ a material-dependent scalar creep rate law defined below, $\sigma_{v}$ the von Mises stress, and $\operatorname{dev}(\boldsymbol{\sigma})$ the deviatoric stress defined as

$$
\operatorname{dev}(\boldsymbol{\sigma})=\boldsymbol{\sigma}-\frac{1}{3} \operatorname{trace}(\boldsymbol{\sigma}) \mathbf{I}
$$

\footnotetext{
1 Except for 52Ni-22Cr-13Co-9Mo, Alloy 617 (UNS N06617) where the values are referenced below.
} 
with $\operatorname{trace}(\boldsymbol{\sigma})$ the sum of the normal stresses.

In the following log refers to the logarithm base 10 .

Scalar creep law for $304 S S$

$$
\dot{\varepsilon}_{c}=A\left(\sinh \frac{\beta \sigma_{v}}{n}\right)^{n} \exp \frac{-Q}{R(T+273.15)}
$$

with constants

$$
\begin{gathered}
A=1.38 \times 10^{13} \\
\beta=145.037681\left[-3.652 \times 10^{-4}+7.518 \times 10^{-7}(T+273.15)\right] \\
n=6 \\
Q=67000 \\
R=1.987
\end{gathered}
$$

This model is applicable for temperatures between 427 and $816^{\circ} \mathrm{C}$ and for times not greater than 300,000 hours.

\section{Scalar creep law for $316 S S$}

$$
\dot{\varepsilon}_{c}=A\left(\sinh \frac{\beta \sigma_{v}}{n}\right)^{n} \exp \frac{-Q}{R(T+273.15)}
$$

with constants

$$
\begin{gathered}
A=\left\{\begin{array}{cc}
5.6229 \times 10^{12} & 427 \leq T<538 \\
-7.8535 \times 10^{15}+9.6933 \times 10^{12}(T+273.15) & 538 \leq T<579 \\
5.28787 \times 10^{-6} \exp \left(\frac{39057.1}{T+273.15}\right) & 579 \leq T<649 \\
6.03371 \times 10^{10} \exp \left(\frac{4967.76}{T+273.15}\right) & 649 \leq T \leq 816
\end{array}\right. \\
\beta=\left\{\begin{array}{cc}
-80.9236+0.105455(T+273.15) & 538 \leq T<579 \\
50.1136-0.0482143(T+273.15) & 579 \leq T<649 \\
14.4647-9.54954 \times 10^{-3}(T+273.15) & 649 \leq T \leq 816
\end{array}\right. \\
Q=67000 \\
R=1.987
\end{gathered}
$$


This model is applicable for temperatures between 427 and $816^{\circ} \mathrm{C}$ and for times not greater than 300,000 hours.

\section{Scalar creep law for Ni-Fe-Cr UNS N08810}

$$
\dot{\varepsilon}_{c}=\left(\frac{\sigma_{v}}{\sigma_{0}}\right)^{n}
$$

with constants

$$
\begin{gathered}
\sigma_{0}(T)=0.23159 \exp \left(\frac{6880.36}{T+273.15}\right) \\
n(T)=2.65647 \times 10^{-7}(T+273.15)^{3}-7.16734 \times 10^{-4}(T+273.15)^{2} \\
+0.64084(T+273.15)-180.989
\end{gathered}
$$

This model is applicable for temperatures between 427 and $760^{\circ} \mathrm{C}$ and for times not greater than 300,000 hours.

Scalar creep law for $2 \frac{1 / 4 C r-1 M o}{4}$

$$
\begin{gathered}
\dot{\varepsilon}_{c}= \begin{cases}\dot{\varepsilon}_{2} & \sigma_{v}<60 \\
\dot{\varepsilon}_{H} & \sigma_{v} \geq 60\end{cases} \\
\dot{\varepsilon}_{H}= \begin{cases}\dot{\varepsilon}_{1} & T \leq 13.571 \sigma_{v}^{0.68127}-1.8 \sigma_{v}+437.63 \\
\dot{\varepsilon}_{2} & T>13.571 \sigma_{v}^{0.68127}-1.8 \sigma_{v}+437.63\end{cases} \\
\dot{\varepsilon}_{1}=\frac{10^{\left(6.7475+0.011426 \sigma_{v}+\frac{987.72}{U} \log \sigma_{v}-\frac{13494}{T+273.15}\right)}}{100} \\
\dot{\varepsilon}_{2}=\frac{10^{\left(11.498-\frac{8.2226 U}{T+273.15}-\frac{20448}{T+273.15}+\frac{5862.4}{T+273.15} \log \sigma_{v}\right)}}{100}
\end{gathered}
$$

and with parameter $U$ interpreted linearly as a function of temperature from Table I-8

Table I-8 Parameter $U$ for the $21 / 4 \mathrm{Cr}-1$ Mo scalar creep law

\begin{tabular}{|l|l|}
\hline$T$ & $U$ \\
\hline 371 & 471 \\
\hline 400 & 468 \\
\hline 450 & 452 \\
\hline 500 & 418 \\
\hline 550 & 364 \\
\hline 593 & 295 \\
\hline
\end{tabular}

This model is applicable for temperatures between 371 and $593^{\circ} \mathrm{C}$ and for times not greater than 300,000 hours.

\section{Scalar creep law for $9 \mathrm{Cr}-1 \mathrm{Mo}-\mathrm{V}$}




$$
\dot{\varepsilon}_{c}=C \sigma_{v}^{n} \exp \left(V \sigma_{v}\right) \exp \left(\frac{-Q}{T+273.15}\right)
$$

with constants

$$
\begin{gathered}
C=2.25 \times 10^{22} \\
n=5.0 \\
V=0.038 \\
Q=77280
\end{gathered}
$$

This model is applicable for temperatures between 371 and $649^{\circ} \mathrm{C}$ and for times not greater than 300,000 hours.

Scalar creep law for 52Ni-22Cr-13Co-9Mo, Alloy 617 (UNS N06617)

$$
\dot{\varepsilon}_{c}=\dot{\varepsilon}_{0} \exp \left(\frac{B \mu b^{3}}{A k(T+273.15)}\right)\left(\frac{\sigma}{\mu}\right)^{\frac{-\mu b^{3}}{A k(T+273.15)}}
$$

with constants

$$
\begin{gathered}
\dot{\varepsilon}_{0}=1.656 \times 10^{7} \\
A=-4.480 \\
B= \begin{cases}-2.510 & T \leq 775 \\
-3.174 & T>775\end{cases} \\
\mu=\frac{E}{2(1+v)}
\end{gathered}
$$

with $E$ the temperature-dependent Young's modulus for 52Ni-22Cr-13Co-9Mo from Table TM of Section II, Part D (Metric) and $v$ the Poisson's ratio for 52Ni-22Cr-13Co-9Mo from Table PRD of Section II, Part D(Metric),

$$
\begin{gathered}
b=2.019 \times 10^{-7} \\
k=1.38064 \times 10^{-20}
\end{gathered}
$$

This model is applicable for temperatures between 427 and $954^{\circ} \mathrm{C}$ and for times not greater than 100,000 hours.

I-9. Simplified Inelastic Analysis. A finite element analysis with the following characteristics:

(1) A steady state temperature $T_{\text {design }}(x)$ is specified.

(2) The strain-displacement relations are those of small displacement gradient theory.

(3) The material model shall be based on the simplified inelastic model of Mandatory Appendix I8. 
(4) The specified load system $L_{\text {design }}$ is applied as the initial elastic step and it is then held constant until the end of the specified load duration.

(5) The time history of the stress redistribution in the numerical model after the initial load application is determined from this simplified inelastic analysis.

\section{I-10. Cumulated Creep Damage Calculation from Simplified Inelastic Analysis.}

A time-fraction definition is used for the cumulated creep damage, $D_{c}^{i}(x)$, for the Load System $L_{i}$, at a point $x$ and for the specified time duration $t_{i}$ :

$$
D_{c}^{i}(x)=\int_{0}^{t_{i}} \frac{d t}{t_{M}\left(\sigma_{e}(x, t)\right)}
$$

This calculation is performed using the time history of the stresses at the point $x$ from the simplified inelastic analysis for the full specified time duration of the service loading. For each point $x$ at time $t$ the effective stress $\sigma_{e}(x, t)$ is

$$
\sigma_{e}(x, t)=\max \left\{\begin{array}{l}
\sigma_{1}(x, t) \\
\sigma_{v}(x, t)
\end{array}\right.
$$

with $\sigma_{1}(x, t)$ the maximum tensile principal stress (or zero if all three principal stresses are compressive) and $\sigma_{v}(x, t)$ is the von Mises stress.

The time $t_{M}$ is the time such that the effective stress $\sigma_{e}(x, t)$ equals the minimum-stress-to-rupture $M\left(x, t_{M}\right)$ defined in I-7, i.e. the time $t_{M}$ such that

$$
\sigma_{e}(x, t)=M\left(x, t_{M}\right)
$$




\section{NONMANDATORY APPENDIX A ALTERNATIVE GLOBAL SERVICE CHECK}

This alternate procedure shall be used in conjunction with the definitions given in Mandatory Appendix I and the additional definitions given in A.3.

\section{A.1. Requirements.}

The designer may use this procedure to assess the component against the Global Service Check (2.3.1) if the following requirements are met:

1. For all Service Loadings the steady state temperature distribution $T(\boldsymbol{x})$ shall be translated to zonal Specified Temperatures per HBB-3112.2. These zonal temperatures are used as the design temperature distribution $T_{\text {design }}(\boldsymbol{x})$ only for assessing the component against the Global Service Check using these alternate criteria. The Local Service Check must still be completed using the full steady state temperature distribution $T(\boldsymbol{x})$.

2. For all Service Loadings there must exist only a single temperature zone in the analyzed component. That is, for each Service Loading the design temperature distribution $T_{\text {design }}(\boldsymbol{x})$ must be isothermal. This temperature can then be expressed as $T_{\text {design }}$, which does not vary with position in the component.

This alternate procedure can be significantly more conservative than the base procedure in 2.3.2 when analyzing components with welds.

\section{A.2. Alternative Global Service Check Acceptance Procedure.}

STEP 1 - EPP analysis.

For each load case $i$ :

(i) Set the pseudo yield stress $Y$ to an arbitrary value $S_{\text {arb }}$ (for example a unit stress) everywhere in the component.

(ii) Perform a limit load analysis per A.3.1 to determine the limit load multiplier $f_{i}$ for the specified loading system $L_{\text {design }}^{i}$. The temperature at $x$ shall be the isothermal zonal temperature $T_{\text {design }}^{i}$.

STEP 2 - Maximum life calculation.

For each load case $i$ :

(i) Calculate the maximum allowable pseudo yield stress based on the limit load multiplier $S_{\text {max }}^{i}=S_{a r b} / f_{i}$ with the load multiplier $f_{i}$ defined in A-3.

(ii) Use Table I-4 to determine the maximum allowable time, $t_{\max }^{i}$, corresponding to the maximum allowable pseudo yield stress $S_{\text {max }}^{i}$ :

a. For Service Load A or B and components not containing weldments the maximum time $t_{\text {max }}^{i}$ is the time for which

$$
S_{\text {max }}^{i}=\sqrt{3 / 4} \times S_{m t}\left(T_{\text {design }}^{i}, t\right)
$$


If $S_{\text {max }}^{i}>\sqrt{3 / 4} \times S_{m}\left(T_{\text {design }}^{i}\right)$ the component does not pass the Global Service check criteria.

b. For Service Level C and components not containing weldments the maximum time $t_{\text {max }}^{i}$ is the time for which

$$
S_{\text {max }}^{i}=\sqrt{3 / 4} \times S_{t}\left(T_{\text {design }}^{i}, t\right)
$$

If $S_{\max }^{i}>\sqrt{3 / 4} \times 1.2 S_{m}\left(T_{\text {design }}^{i}\right)$ the component does not pass the Global Service check criteria.

c. For Service Level A or B and components containing weldments the maximum time $t_{\text {max }}^{i}$ is the lesser of the times for which

and

$$
S_{\text {max }}^{i}=\sqrt{3 / 4} \times S_{t}\left(T_{\text {design }}^{i}, t\right)
$$

$$
S_{\max }^{i}=\sqrt{3 / 4} \times 0.8 \times R\left(T_{\text {design }}^{i}, t\right) \times S_{r}\left(T_{\text {design }}^{i}, t\right)
$$

If $S_{\text {max }}^{i}>\sqrt{3 / 4} \times S_{m}\left(T_{\text {design }}^{i}\right)$ the component does not pass the Global Service check criteria.

d. For Service Level C and components containing weldments the maximum time $t_{\max }^{i}$ is the lesser of the times for which

and

$$
S_{\text {max }}^{i}=\sqrt{3 / 4} \times S_{t}\left(T_{\text {design }}^{i}, t\right)
$$

$$
S_{\text {max }}^{i}=\sqrt{3 / 4} \times 0.8 \times R\left(T_{\text {design }}^{i}, t\right) \times S_{r}\left(T_{\text {design }}^{i}, t\right)
$$

If $S_{\text {max }}^{i}>\sqrt{3 / 4} \times 1.2 S_{m}\left(T_{\text {design }}^{i}\right)$ the component does not pass the Global Service check criteria.

STEP 3 - Use fraction acceptance criteria.

The acceptance criteria is the sum over the load cases:

$$
\sum_{i} \frac{t_{\text {design }}^{i}}{t_{\text {max }}^{i}} \leq 1
$$

If the component passes this criterion proceed to the Local Check (2.3.2). If not either the component geometry or the Service Loadings must be altered.

\section{A.3. Additional Definitions.}

\section{A.3.1. Limit load analysis.}

A limit load analysis is an EPP analysis with the specified pseudo yield stress $Y$ and temperature $T$ as defined in I-6 except:

(i) The limit load factor $f$ is the maximum load factor $m$ for which the analysis converges.

(ii) The analysis shall continue beyond a load factor of $m=1$, if necessary, until the analysis fails to converge.

As with the base EPP analysis, this procedure is best completed in a finite element framework by incrementally increasing the load until the model fails to converge. 


\section{Commentary}

This chapter summarizes the development of the Code Case language, focusing on particular choices on the analysis methods, allowable stresses, and step-by-step implementation of the draft rules. The subsequent chapter describes how the new design procedure was verified against the existing Section III, Division 5, Subsection HB, Subpart B design-by-elastic-analysis rules and other primary load design approaches.

The core of the new primary load code case rules are three design checks:

1. Global Design check using an EPP analysis

2. Global Service check using an EPP analysis

3. Local Service check using simplified inelastic analysis and the Code minimum stress-torupture data.

The first two checks use the existing Division 5 allowable stresses $S_{o}$ and $S_{m t}$, respectively, and are notionally equivalent to the current primary load design method in HBB-3220 while avoiding stress classification. The third check does not have a direct analog to the current Code rules, though it only uses material information contained in the current Code. The purpose of including this new check is to screen out designs with unacceptable stress concentrations early in the design process. Any design that fails check \#3 in the proposal would also fail the current creep-fatigue design rules in Appendix HBB-T. However, with the new proposed method the designer would find that out much earlier in the process and using a greatly simplified analysis, compared to the creep-fatigue rules, thus saving them a great deal of time. Additionally, the local check provides a check on the Global Service check by preventing the full redistribution of stress if the material and component geometry could not achieve the fully-redistributed stress state in actual service.

The Global Design check uses the Specified Design Temperature. The Service checks use the steady-state temperature distribution. This general approach follows the current Division 5 primary load design practice. Unlike the current primary load design method, the designer can use the actual, non-uniform temperature distribution in the component, rather than use specified averaged zonal temperatures per HBB-3112.2. The full steady-state temperature field is a more accurate representation of the temperature distribution in the in-service component. We assume the concept of a zonal temperature was introduced to the Code to simplify the design analysis. Modern computer analysis can easily work with the full temperature field.

Furthermore, unlike the current Code which classifies (most) thermal stresses as secondary loads, the stress analysis for the Service checks includes thermal stresses. The thermal stresses will not affect the results of the Global Service check, but will affect the results of the Local Service check. For the global checks the thermal stresses are included in the analysis as a convenience to the designer - omitting them will not significantly change the results of the analysis as they are, by definition, self-equilibrating. This convenience can be viewed as the logical outcome of one of the stated goals of the new design method: to avoid the 
stress classification processes. Including the thermal stresses is a necessary part of the local check, as described in further detail below.

\subsection{Global Checks}

The analysis tool used in checks \#1 and \#2 is a limit load analysis. The concept is to select a pseudo yield stress based on the Code allowable stresses, the temperature, and (for Service Loads), the design life. The acceptance criteria are based on a finite element analysis of the component using an elastic perfectly-plastic material model with temperature dependent elastic properties (from Section II, Part D) and a temperature dependent yield stress equal to the pseudo yield stress. The designer executes the limit load analysis by increasing the loading on the model incrementally until the analysis fails to converge. The load at which the analysis fails to converge is the limit load.

The design check compares the actual loads to the limit loads for the given pseudo yield stress - if the actual loads are less than the limit load for a pseudo yield stress based on the relevant allowable stress then the component passes the check. This analysis approach allows for full load redistribution - i.e. the component can redistribute stress freely to remain below the specified pseudo yield stress. This is the key difference from the current designby-elastic-analysis approach in HBB, which only allows redistribution across a single section via the section factors and does not allow for structural load redistribution via redundant load paths. This explains why the new EPP Global Design and Service checks produce somewhat less restrictive designs than the design-by-elastic-analysis method, even though they use the same allowable stresses (see below).

There are a few complications to this simple limit load acceptance criteria:

- The definition of the current HBB allowable stress varies based on the type of loading Design or Service Load - and, for Service Loads, the Service Level (A, B, or C) and whether the material is weldment or base metal.

- The current design by elastic analysis procedure in the Code uses a Tresca criteria (i.e. the stress intensity), which would be difficult to implement in FEA. Instead the new pro- 
cedure uses a standard von Mises yield surface and associated flow rule but scales the allowable stresses to account for the difference between the Mises and Tresca yield surfaces. The scaling factor was selected so that:

o The new EPP checks produce exactly the same section thickness/allowable pressures/design lives as the current design by elastic analysis methods for a 2:1 biaxially stressed component (i.e. a thin-walled cylindrical vessel away from discontinuities).

o This scale factor is the most conservative for any general state of stress (i.e., it is based on the greatest difference between the von Mises and Tresca yield surfaces).

- For Service Loads the current Code requires the designer to combine the effect of all the loadings together. The proposal does this with a time fraction scheme which, conceptually, is given as:

$$
\sum_{i} \frac{\text { actual time at load }}{\text { maximum allowable time }} \leq 1
$$

where the sum takes place over all the individual Service Load cases, the actual time at load is given in the Design Specification, and the maximum allowable time is the maximum time the structure could sustain the loads while staying at or below the Code allowable stresses.

The proposed design rules guide the designer towards the maximum allowable time for each case via iteration. That is, the designer chooses some trial life greater than the actual time at load, runs the EPP limit load analysis, and finds out if the check passes. They repeat this for each load case and calculate the time fraction using these trial lives. If all the individual cases pass the limit load criteria and the life fraction scheme, using the trial lives, passes then the overall design check passes. This procedure allows the use of a trial life greater than the optimal maximum life because this approach is conservative and avoids requiring the design determine the exact maximum allowable life. If either the limit load check for a case fails or the time fraction sum fails the designer needs to increase some of the trial times and try again.

The trial time iteration process guides the designer towards the actual maximum allowable time for each case. If the component fails the time fraction check even having found these 
maximum allowable times then it fails the EPP criteria - the geometry or loadings must be altered.

In general, the method requires the designer to execute more than one EPP analysis for each Service Load case. That said, if the designer has a good feel for the component, they should be able to quickly select trial lives that allow the checks to pass with a minimum of iteration.

The EPP limit load and trial life approach are the basic building blocks for the Global Design and Service checks. The actual design procedure, detailed in Chapter 2, includes a few additional details:

\subsubsection{Global Design Check}

The Global Design Check retains the Design Loading concept from the base Code. The Design Loads are a set of loads (pressure, isothermal temperature, and nozzle loads) that bound the standard operation, Service Level A service loads. This Code Case allows the designer to ignore nozzle loads and other applied forces in the Global Design Check. The rational is that the Code Case allows the user to "fall back" on the design by rule formula in HCB-3300, HCB-3400, HCB-3500 and HCB-3600. These design by rule formula exclude nozzle loads, redirecting the user to the $\mathrm{HBB}$ design by elastic analysis rules this Code Case replaces for cases with a nozzle load. For this check the temperature field is isothermal and equal to the specified Design Temperature.

The allowable stresses for the Design Check, $S_{o}$, are not time-dependent. As such, trial life iteration is not required for the Global Design Check. A single limit load analysis determines if the component passes or fails the EPP design criteria.

The Design Check does not consider weldments and so the component will have a single value of the pseudo yield stress throughout.

\subsubsection{Global Service Check}

Again, the Global Service Check retains the base Code framework of a set of transient Service Load conditions categorized based on frequency and severity. The definition of the allowable stress changes depending on the Service Level of the loading and whether the material is in a weldment or base material region. Furthermore, while the Code presents individual allowable stress checks for Service Levels A, B, and C, the limiting criteria if the Design Specification provides more than a single Service Load is a time-fraction combination of all the individual Service Loads.

The EPP design rules retain all these features. Table I-4 defines the appropriate pseudo yield stress for each Service Level in terms of the base Code allowable stresses. This table provides definitions for both weld and base material. The analysis uses the full steady-state temperature distribution to capture the spatial dependence of the material allowable stress. The design procedure uses the trial time iteration scheme to execute the Code time-fraction sum.

\subsection{An Alternative Approach: Equilibrium Field Scaling}

One of the goals for the new primary load design method, described in the introduction, is to reduce the complexity of the design rules and speed up the overall design process. The trial 
time iteration approach used in the base proposed Code rules is less than optimal as it can require a designer to execute multiple EPP analyses of the component in order to find the optimal, maximal trial time.

There is an alternative approach that only requires a single EPP analysis to determine the optimal trial time. However, as described in detail below, it can only be applied to certain types of components and requires a simplification of the component temperature field.

Equilibrium field scaling underlies this alternative approach. The idea is to find the component limit load, expressed as a scaled multiple of the actual loads, for an arbitrary pseudo yield stress.

Imagine we have a component where the (unknown) allowable stress is constant throughout the entire component volume and the only applied boundary conditions are pressures and nozzle loads, expressed as tractions. An example is an isothermal component without welds - the allowable stress for such a component will be a constant for any design life. In this situation consider a limit load analysis based on an arbitrary pseudo yield stress $S_{\text {arb }}$ for the loading set $P$. A limit load analysis is an EPP analysis of the component with a constant pseudo yield stress $S_{a r b}$. The analysis increases the loads incrementally until the analysis fails to converge. This limit load analysis considers the scaled actual loads, i.e. the load set $\bar{P}=f P$. The output of the analysis is the (maximum) scale factor $f$. Let the equilibrium stress field at the limit load be $\bar{\sigma}(x)$.

Imagine the component now under the uniformly scaled equilibrium stress field $\sigma(x)=$ $\frac{1}{f} \bar{\sigma}(x)$. This scaled stress field is in equilibrium with the actual applied loads. To demonstrate this, consider a generic traction boundary condition. In the limit load analysis, the local differential expression of equilibrium is

$$
\bar{T}=\bar{\sigma} \cdot n
$$

the corresponding equilibrium equation for the scaled stress field is

$$
T=\sigma \cdot n=\frac{1}{f} \bar{\sigma} \cdot n=\frac{1}{f} \bar{T}
$$

and so

$$
\bar{T}=f T
$$

demonstrating that the scaled equilibrium stress field is in equilibrium with the actual applied service loads.

Scaling the limit load stress field provides a stress field in equilibrium with the actual applied loads. However, this stress field may not be feasible - it may not satisfy the material constitutive law or result from a compatible strain field. The scaled stress field certainly does not satisfy the yield criteria for the original arbitrary pseudo yield stress $S_{a r b}$. For example, consider a problem which yields under the application of the original limit load $\bar{P}$. The von Mises stress at some point in the component is then equal to the yield stress $S_{a r b}$. For the scaled equilibrium stress field, the von Mises stress at that same point is equal to $\frac{1}{f} S_{a r b}$, 
which clearly does not satisfy the yield condition. However, now consider a scaled pseudo yield stress $S=\frac{1}{f} S_{a r b}$. The scaled equilibrium stress field obeys the yield condition for this scaled pseudo yield stress.

This leaves only the compatibility requirement. As it turns out, the scaled equilibrium stress field may not result from a compatible strain field. However, a classical result of plasticity theory states that the scaled pseudo yield stress, $S=\frac{1}{f} S_{a r b}$, is a lower bound on the exact, actual pseudo yield stress that just results in collapse in the component under the actual loads $P$ [3]. This is a corollary of the lower bound plastic collapse theorem.

This result (see the reference for a detailed proof) means it is conservative to use the scaled pseudo yield stress $S=\frac{1}{f} S_{\text {arb }}$ as the maximum allowable pseudo yield stress. The design life corresponding to this maximum allowable pseudo yield stress can be determined from the definition of the pseudo yield stress in terms of the allowable stress (Table I-4 in the Code Case) and the table of allowable stresses in the Code. This is the maximum possible design life used in the time fraction summation.

This approach provides the designer with the best-possible trial time for use in the time-fraction summation calculation without iteration - it requires a single EPP analysis plus a simple spreadsheet calculation. This is considerably easier than the trial time iteration method described previously.

However, the equilibrium field scaling technique has a serious disadvantage - it only works if the pseudo yield stress/allowable stress is either the same for all locations in the component or if the ratio between the pseudo yield stress/allowable stress at different locations in the component is fixed and known before the start of the analysis. This limitation means that the method does not apply to non-isothermal components or to components with welds.

Nonmandatory Appendix A of the draft Code Case allows the designer to replace the trial time iteration Global Service Check with an alternative approach using the equilibrium field scaling method. The Code Case implementation of equilibrium field scaling avoids the trouble with non-isothermal components by allowing the designer to use the specified zonal temperature of the base Code to approximate the component temperature field as homogeneous. The designer may apply the Appendix A approach to components with welds, however as written it will require the designer to use the weld allowable stress to calculate the maximum life - essentially treating the entire component as a weldment. This is likely to be too overconservative for many structures.

Despite its limitations, the equilibrium field scaling approach can save designers considerable effort for some types of components. As such, the draft code case provides it as alternative means to satisfying the Global Service Check.

\subsection{Local Service Check}

\subsubsection{General Approach}

The Global Checks (both Design and Service and including the alternate equilibrium field scaling technique) allow full redistribution. That is, the only limit on load redistribution 
within the component is the limit load, i.e. full plastic collapse. In actuality, creep in some Class A materials may not be capable of fully redistributing the initial stress. An extreme example would be a brittle material, essentially not capable of redistribution whatsoever. None of the qualified Class A materials are brittle, but some may have inefficient creep ductility to fully redistribute the initial stress for some highly redundant structures and in some operating conditions.

To guard against this potential defect of the Global EPP checks, the draft Code Case includes a Local Service Check. The local check is based on the current Division 5, HBB-T creep damage criterion, which is a time fraction summation (HBB-T-1420):

$$
D_{c}=\int \frac{d t}{t_{R}(\sigma)}
$$

where $t_{R}(\sigma)$ is the time to rupture based on the minimum stress-to-rupture data in the Code. The local check applies the simple criterion

$$
\sum_{i} D_{c}^{i} \leq 1
$$

where the sum is over each individual Service Load case and the check has to pass for all locations in the component.

Applying this criterion requires the stress and temperature of each point in the component as a function of time as well as a map between the stress tensor and a scalar indexed to the Code minimum stress-to-rupture tables to predict failure (an "effective stress measure").

For the stresses and temperatures the proposed code rules use an elastic-creep stress analysis and the steady-state temperature field. This analysis includes the thermal stresses attributable to the steady state temperatures. During the analysis the creep model will tend to relax away these thermal stresses. However, during the initial part of the analysis during relaxation the partially-relaxed thermal stresses contribute to creep damage. The draft rules require an elastic-creep damage calculation for each Service Load case and sum the resulting damage fractions.

This approach provides a check against excessive redistribution by explicitly calculating the damage caused by stress relaxation and redistribution. Indexing damage to the Code minimum stress-to-rupture, rather than the allowable stresses, means for simple structures with minimal thermal stresses and low geometric stress concentration the base, EPP Global Checks will control over the Local Check for the ductile Class A materials. However, for complex structures or components with high thermal stresses this additional local criteria guards against poor designs.

In addition to preventing excess stress redistribution the Local Check also screens out poor geometric designs early in the HBB design process. HBB has two types of design criteria: primary load allowable stress criteria and criteria on the deformation-controlled quantities (creep-fatigue and ratcheting). The current HBB rules for primary load design do not consider peak stress, meaning they do not guard against poor geometric designs with excessive stress concentration that may lead to premature creep failure. The rules taken as a whole do prevent such designs because the current HBB creep-fatigue design criteria (in Appendix 
HBB-T) includes a relaxation creep damage calculation, either using a full inelastic analysis or with a design by elastic analysis method. However, this creep-fatigue check is customarily the last in the HBB design sequence as primary load design is typically used to establish the trial component dimensions and the creep-fatigue checks require information calculated during the strain accumulation checks.

The primary local check provides a screening test to guard against poor geometric features early in the design process. The creep-fatigue check is more rigorous than the simple relaxation analysis required by these draft primary load design rules - it includes fatigue damage and creep-fatigue interaction, accounts for time-independent plasticity, and has a more realistic representation of stress relaxation. However, the simple elastic-creep analysis in the draft rules provides an early screening test for poor geometric designs that will later fail the full creep-fatigue check. The Local Service check then serves two functions: it guards against excess stress redistribution otherwise allowed by the EPP Global Checks and also screens out designs with excessive stress concentrations early in the design process.

\subsubsection{Material Model}

The draft rules require an elastic-creep constitutive model (plus thermal properties) to complete the analysis. The method bases the creep law on the average material minimum creep rate. The analysis neglects any time-independent plasticity. This form of analysis is conservative - it will generally produce higher stresses than in the actual component because:

1. The model does not include any rate-independent plasticity and so the initial stresses will be higher than the actual component stresses, which will be limited by the material yield stress (and subsequent work hardening).

2. The minimum creep rate, by definition, bounds the actual creep rate experienced by a material point. Therefore, stress relaxation in the simplified model will be slower, stresses higher, and creep damage greater than in the actual component.

Section II, Part D of the ASME Code tabulates the elastic and thermal properties for the Class A materials. This only leaves the definition of the minimum creep rate model to complete the constitutive law.

Currently, HBB provides deformation models for the Class A materials in the form of isochronous stress-strain curves. These curves plot the material stress-strain relation at fixed times, calibrated to uniaxial tension and creep test data. The dataset is much sparser than the relations plotted in the Code, which implies that the curves were generated from a model for elastic, plastic, and creep strain as a function of temperature, time, and stress.

A recent effort at ASME uncovered the original equations used to generate the Code isochronous stress-strain curves for the Class A materials (ASME C\&S Record 18-2750). These equations will be incorporated, along with the curves themselves, into the 2021 edition of the Code.

The minimum creep rate models provided in the draft Code Case are based on the models underlying the current Code isochronous curves. This means that the minimum creep rate models agree with the current Code description of the material-average minimum creep rate as a 
function of stress and temperature. Essentially, the models incorporated into the new primary load design rules are simply the minimum creep rate term extracted from the full isochronous curve creep model. However, there were several material-specific difficulties encountered during this process.

\subsubsection{304H Stainless Steel}

The original source for the isochronous curve models is [4]. These equations contain a readily-identified minimum creep rate term.

\subsubsection{316H Stainless Steel}

The original source for the isochronous curve models is [4]. These equations contain a readily-identified minimum creep rate term.

\subsubsection{Alloy $800 \mathrm{H}$}

The original source for the isochronous curve models is [5]. The creep rate equation in this original source does not reach a minimum value. The model is essentially entirely primary creep, describing a continually decreasing creep rate as a function of time. Reference [6] describes in detail the process used to extract a suitable minimum creep rate model from the model underlying the Code isochronous stress-strain curves. Essentially, the method selected was to tabulate the creep rate predicted by the original model for various temperatures and stresses covering the HBB temperature range and expected operating stresses at a time equal to $\frac{2}{3} t_{R}$, where $t_{R}$ is the Code time to rupture corresponding to the applied stress. The model in the current draft rules is a power law fit to this database, which very accurately recovers the discrete temperature, stress, creep rate data.

There are several compromises in this process but they tend to shift the model to more conservative, slower, creep rates. Two-thirds of the time to rupture is a crude approximation of the typical time to minimum creep rate for alloys like $800 \mathrm{H}$. However, using the Code minimum time to rupture, as opposed to the average time to rupture, will tend to produce a shorter time to minimum creep rate than in the actual material. This is significant as the creep model underlying the $800 \mathrm{H}$ isochronous curves produces a continuously decreasing creep rate as a function of time at fixed stress and temperature. This implies that using a shorter time compared to the true time to minimum will result in slower creep rates, which are more conservative for use in the primary load design method.

\subsubsection{2.25Cr-1Mo}

The original sources for the isochronous curve models are [7], [8]. These references describe a very convoluted creep rate model. However, the model does represent a minimum creep rate behavior, though extracting that minimum rate as a function of stress and temperature is not trivial. The model described in the current proposal is a new equation calibrated to match the minimum creep rates from the original isochronous model. A technical note submitted for publication to the Journal of Pressure Vessel Technology describes the details of deriving 
the simplified minimum creep rate model. The differences between the original model minimum creep rate as a function of temperature and stress and the new model are negligible, and so the model proposed here matches the HBB isochronous curves.

\subsubsection{9Cr-1Mo-V (Grade 91)}

The original source for the isochronous curve model is [9]. The original model has a definite minimum creep rate term. The creep model in the proposed rules extracts that term from the full creep formulations.

\subsubsection{Alloy 617}

The original source for the isochronous curve model is [10]. The original model as a definite minimum creep rate term.

\subsubsection{Effective Stress}

Given the definition of the Service Loading and the appropriate constitutive model the designer can simulate the full relaxation history of the component. At each point in the structure the result of this simulation is the full stress tensor as a function of time, at fixed (steadystate) temperature. Calculating creep damage requires a map from the full stress tensor, 3D in the general case, to a scalar stress measure. The creep damage calculation indexes this scalar stress measure into the current Code minimum stress-to-rupture $\left(S_{r}\right)$ table to calculate a damage fraction, as described above.

This map between the 3D stress tensor and scalar is called an effective stress measure. The literature contains a wide variety of proposed effective stress measures, some of which have material-dependent constants (c.f. [11], [12]). The current Section III, Division 5, Subsection HB, Subpart B Appendix T rules for creep-fatigue using design by inelastic analysis apply 
the Huddleston effective stress in the creep damage calculation [13]. The Code provides the required material-dependent coefficient [14], [15].

The proposed primary load design rules use a different effective stress:

$$
\sigma_{e}=\max \left\{\sigma_{1}, \sigma_{v}\right\}
$$

where $\sigma_{1}$ is the maximum principal tensile stress and $\sigma_{v}$ is the von Mises stress. Several factors went into the selection of this effective stress measure:

1. This effective stress measure has no material-dependent coefficients, which simplifies the rules and also simplifies the future task of adding new materials to the Code Case.

2. This measure bounds several of the effective stress measures proposed in the literature (i.e. [11]) which are additive combinations of the maximum principal and von Mises effective stress (with material-dependent weightings).

3. This effective stress measure actually better fits the multiaxial rupture database for heat 9T2796 of 304H stainless steel originally used by Huddleston to justify and calibrate his model in the original paper [13].

4. Recent work at Argonne National Laboratory on crystal plasticity finite element modeling of the microstructural mechanisms underlying creep deformation and rupture in Grade 91 steel (c.f. [16], [17]) demonstrates this effective stress measure best fits the multiaxial failure of Grade 91 under creep conditions, including very long rupture time and triaxial stress simulations that cannot be implemented with experimental tests. This work will appear in an upcoming publication. 



\section{Verification}

This chapter summarizes work done to verify that the designs produced by the new, proposed primary load design procedure are reasonable when compared to the current Section III, Division 5, Subsection HB, Subpart B primary load design process and against other, similar design methods. Most of this chapter is a brief summary of work already published in ASME conference proceedings. However, the chapter also contains a few additional verification analyses unique to this report.

The report entitles this chapter "verification" rather than "validation" because the current Section III, Division 5 primary load design process has already been well validated to produce safe, perhaps over-conservative designs. The focus of this section is then on comparing results from the new, proposed design method to corresponding results using the current design process in order to assess the effect adopting the new technique will have on component designs.

\subsection{Cylindrical Thin-walled Pressure Vessel}

As mentioned in Chapter 3, the scale factor on the von Mises plasticity flow surface in the new, EPP design method produces identical designs as the current method, using the stress intensity, for the standard case of a thin-walled cylindrical pressure vessel.

The stresses in a thinned walled cylinder are biaxial with a 2:1 ratio between the hoop and the axial stress. For this stress state the stress intensity is

$$
\sigma_{I}=\frac{p r}{t} \text {. }
$$

Given the allowable stress $S_{m t}$ the minimum wall thickness is

$$
t_{I}=\frac{p}{r S_{m t}}
$$

The von Mises stress is

$$
\sigma_{v}=\sqrt{\frac{3}{4}} \frac{p r}{t}
$$

The draft code rules apply a factor of $\sqrt{\frac{3}{4}}$ to the allowable stress in the EPP analysis, meaning the minimum wall thickness for the EPP method is

$$
t_{v}=\frac{p}{r S_{m t}}
$$

exactly the same for the old and new design methods.

Additional analysis described in [6] demonstrates that for this case the Local Service check will never control for this simple example - the Global Service check always produces a thicker minimum section. Taken together with the preceding analysis, this demonstrates that 
both the current design by elastic analysis method and the new, proposed EPP method will produce exactly the same designs for a simple cylindrical, thin walled pressure vessel away from stress discontinuities. This suggests that both methods will produce similar designs for the shell of a standard cylindrical vessel.

Serendipitously, the ratio of $\sqrt{\frac{3}{4}}$ is also the bounding ratio between the Tresca and von Mises criteria - it expresses the greatest ratio between the two surfaces. This means that not only is this criterion exact for a relevant component geometry, it also bounds the maximum possible difference between the criteria for any geometry.

\subsection{Redistribution in Bending}

This example considers a second simple structure (see Figure 4.1). The structure is a rectangular beam with height $h$ and width $w$ bent under a simple applied moment per unit width of $M^{\prime}=M / w$. This example compares the maximum allowable moment for a fixed temperature and design life. The example assumes, for the design by elastic analysis calculation, that the temperature and design life are such that the time-dependent allowable stress $S_{t}$ controls. The example considers a Service Level A load.

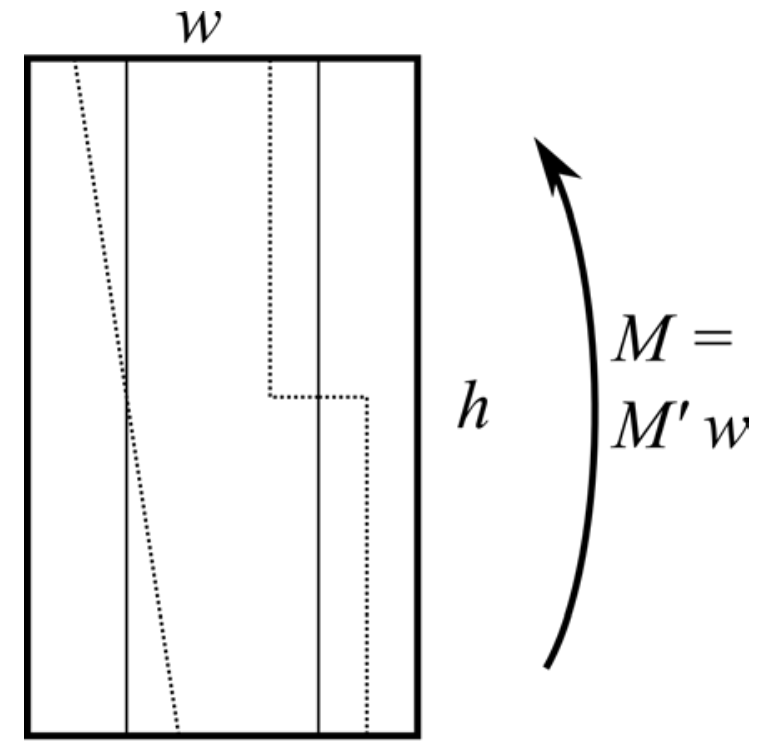

Elastic Fully-plastic

Figure 4.1. Simple bending example. The dotted lines illustrate an elastic and fully-plastic stress distribution. 
The controlling allowable stress equation for the current, design by elastic analysis rules is HBB-3223 equation 5:

$$
P_{L}+\frac{P_{b}}{K_{t}}=S_{t}
$$

with $P_{L}$ the local membrane stress, $P_{b}$ the bending stress, and $K_{t}$ a section factor equal to $5 / 4$ for a rectangular section. For pure bending the membrane stress is zero and the elasticallycalculated bending stress is

$$
P_{b}=\frac{6 M^{\prime} w h}{w h^{3}}=\frac{6 M^{\prime}}{h^{2}} .
$$

The maximum allowable moment is then

$$
M_{\text {elastic }}^{\prime}=\frac{5}{24} S_{t} h^{2} .
$$

The EPP method would allow the section to reach the full plastic distribution, given by

$$
M=\sqrt{\frac{3}{4}} S_{t} \frac{b h^{2}}{4}
$$

where the factor of $\sqrt{\frac{3}{4}}$ is the scaling factor applied by the EPP method to account for the difference in the von Mises and Tresca stress and $\frac{b h^{2}}{4}$ is the plastic section factor. The allowable moment is then

$$
M_{E P P}^{\prime}=\sqrt{\frac{3}{4}} S_{t} \frac{h^{2}}{4} .
$$

Ignoring the scale factor of $\sqrt{\frac{3}{4}}$ the EPP method would allow the beam to carry

$$
\frac{M_{E P P}^{\prime}}{M_{\text {elastic }}^{\prime}}=\frac{S_{t} \frac{h^{2}}{4}}{\frac{5}{24} S_{t} h^{2}}=\frac{6}{5}
$$

times the bending moment as the design by elastic analysis rules. This ratio (1.2) is exactly the ratio between the plastic section factor $(K=1.5)$ and section factor used for creep in the current Code rules $\left(K^{\prime}=1.25\right)$. This increase for the EPP method reflects increased potential for redistribution for the fully-plastic distribution allowed by the EPP procedure whereas the current code uses a section factor based on a power law creep model and a reasonable rate sensitivity exponent.

In general, allowing increased redistribution was a conscious decision - the current elastic procedures do not allow for redistribution for components with redundant load paths. The 
only redistribution the elastic procedure accounts for is stress redistribution in a single section under bending, like in the current example. For this limited case then, the EPP procedure should not allow full redistribution to be consistent with the current Code. The potential for full distribution is mitigated by:

7. The factor of $\sqrt{ }(3 / 4)$ expressing the difference between the von Mises and Tresca criteria. Including the scale factor in the current example gives a ratio of $M_{E P P}^{\prime} / M_{\text {elastic }}^{\prime} \approx$ 1.04 , i.e. the two methods produce nearly the same design.

8. The Local Service check, which realistically limits the potential for the structure to fully redistribute load.

\subsection{Flat-head Vessel}

This example considers a complete, realistic structure: a flat head pressure vessel constructed of $316 \mathrm{H}$ stainless steel. The comparison problem considers a vessel with a fixed geometry and design life and compares the maximum allowable pressure between the current rules and the proposed EPP method.

Figure 4.2 shows the vessel. The component geometry matches the ASME Section VIII, Division 1 design by rule criteria (UG-34) for a Design Temperature of $700^{\circ} \mathrm{C}$ and a Design Pressure of 0.5 MPa. For the Section III, Division 5 Design Load calculation the vessel is isothermal at $700^{\circ} \mathrm{C}$ and the design problem is to find the maximum allowable Design Pressure for a given design life. For the Service Load analysis, Figure 4.2 shows the assumed cycle. The ramp rates are not relevant for the primary load calculation. With this definition, the design problem is again to find the maximum allowable service pressure.

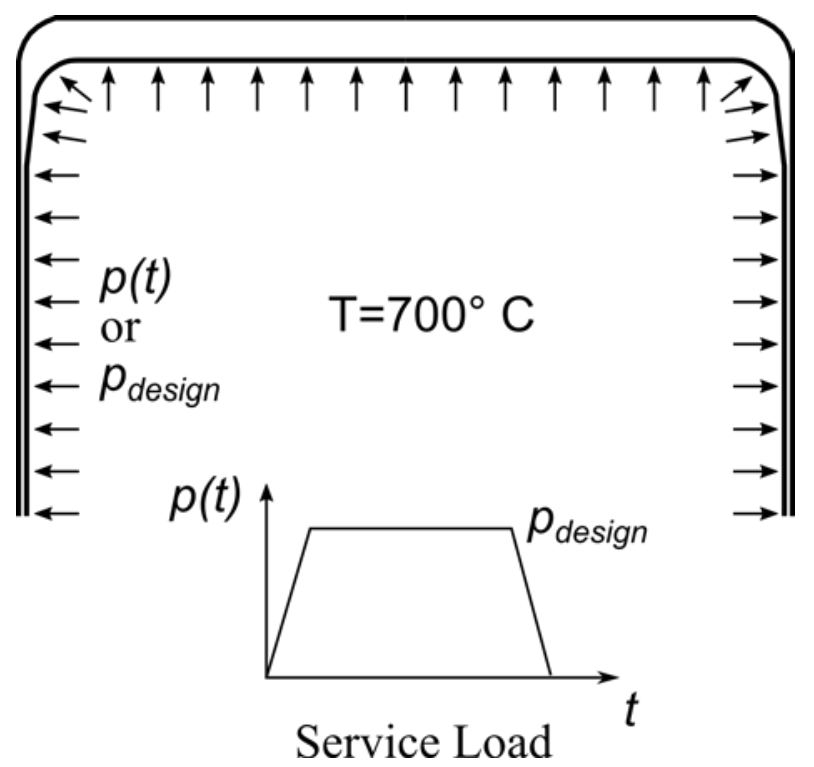

Figure 4.2. Flat head vessel geometry and service load definition. 
Figure 4.3 compares the base design by elastic analysis Design Pressure to the Design Pressure from the proposed EPP Design calculation.

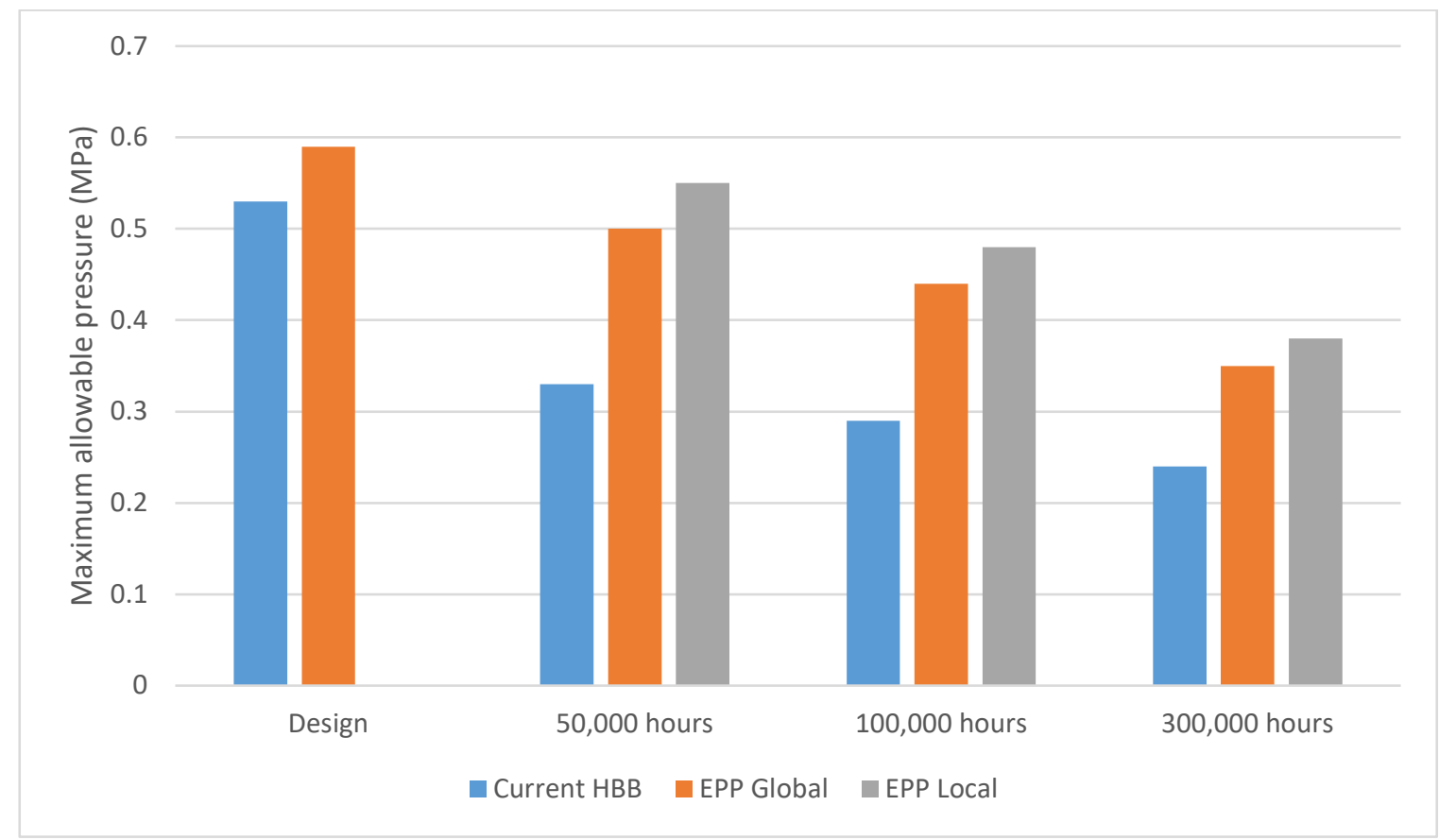

Figure 4.3. Maximum allowable pressures for the flat head vessel for various design methods and design lives.

Figure 4.3 also compares the maximum service pressure for the current Code rules to the maximum service pressures from the EPP Global Service and EPP Local Service checks, plotted separately. The actual maximum service pressure allowed by the new EPP rules would be the lesser of the Global Service and Local Service pressures. For this Service checks the sample problem considers 50,000, 100,000, and 300,000 hour design lives.

Table 4.1 provides the maximum pressure data for all the cases.

Table 4.1. Maximum pressure data for the flat head vessel comparison.

\begin{tabular}{|c|c|c|c|c|c|}
\hline $\begin{array}{l}\text { Design } \\
\text { Life } \\
\text { (hours) }\end{array}$ & $\begin{array}{l}\text { Current } \\
\text { HBB } \\
\text { Design } \\
(\mathrm{MPa}) \\
\end{array}$ & $\begin{array}{l}\text { EPP } \\
\text { Design } \\
(\mathrm{MPa})\end{array}$ & $\begin{array}{l}\text { Current } \\
\text { HBB } \\
\text { Service } \\
\text { (MPa) }\end{array}$ & $\begin{array}{l}\text { EPP } \\
\text { Global Service } \\
(\mathrm{MPa})\end{array}$ & $\begin{array}{l}\text { EPP } \\
\text { Local Service } \\
(\mathrm{MPa})\end{array}$ \\
\hline 50,000 & 0.53 & 0.59 & 0.33 & 0.50 & 0.55 \\
\hline 100,000 & 0.53 & 0.59 & 0.29 & 0.44 & 0.48 \\
\hline 300,000 & 0.53 & 0.59 & 0.24 & 0.35 & 0.38 \\
\hline
\end{tabular}

The results show that generally the new, proposed primary load rules provide higher allowable pressures than the current design by elastic analysis rules, even when using the same allowable stresses. The reason for this is that the new EPP rules allow for redistribution of stress within the component, not simply redistribution within a single section as with the cur- 
rent HBB rules. As creep really does provide a stress redistribution mechanism in high temperature components, this improved design life can be attributed to a reduction in the overconservatism of the current rules, rather than a reduction in the design margin.

Moreover, the Local Service check provides a realistic limitation on the amount of redistribution allowed in the component. For this example, the Local Service check did not constrain the design - the allowable pressure for the Global Service check was always lower than the corresponding allowable pressure for the Local Service check. We anticipate this trend will hold true for all reasonably-design components - recall the flat head geometry was selected using the Section VIII design by rule formula.

For some design lives the allowable service pressure using the EPP method exceed the current maximum design pressure by $50 \%$. This is by far the largest increase observed in any of the verification problems. The likely reason for this increase is that this specific problem - a flat head vessel - is a classic example of the uncertainty in stress classification [18]. There are multiple possible classifications of the pressure stress into primary and secondary, each of which produces a different design. The EPP method avoids this uncertainty and may lead to a better, more balanced distribution of stress producing a higher allowable pressure.

\subsection{Section I/Section VIII Grade 91 Reference Problems}

As part of an effort to update the elevated temperature design rules in Section I and Section VIII of the ASME Code, the BPV VIII Working Group on Elevated Temperature Design formulated a series of reference problems. These reference problems are all, with one exception, realistic Grade 91 components, either in-service components or closely based on actual in-service components. The exception is a $304 \mathrm{H}$ nozzle sphere tested to failure at Oak Ridge 
National Laboratory. Figure 4.4 briefly summarizes the different geometries and loadings. For full details and citations to each individual reference problem see [19].

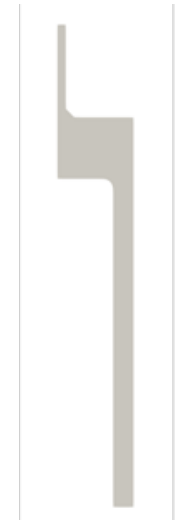

(a) Endplate

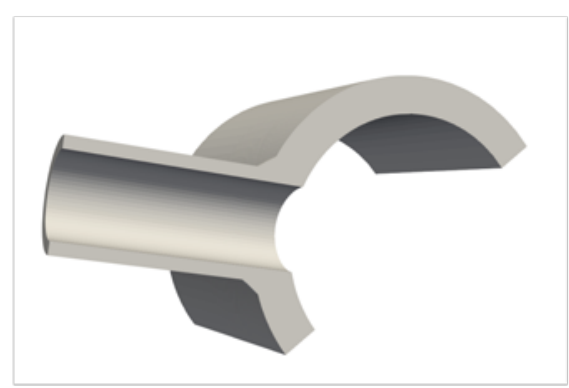

(b) Header

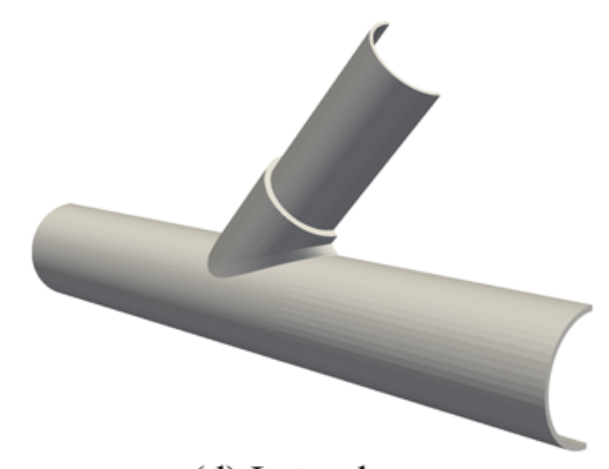

(d) Lateral

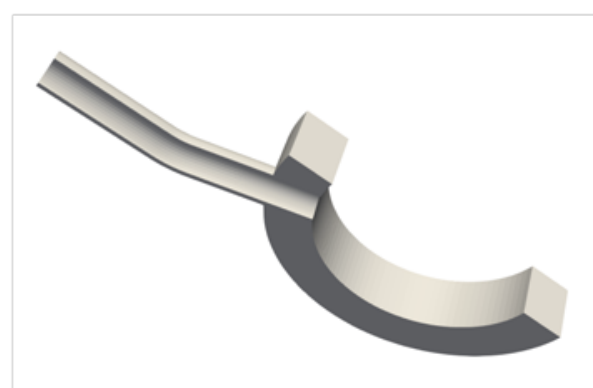

(c) Header "070"

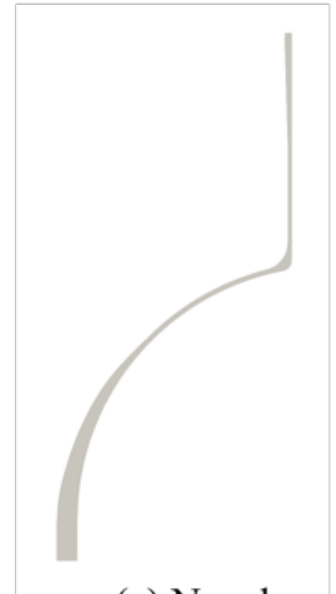

(e) Nozzle-sphere

Figure 4.4. Collection of commercial Section I/VIII sample problems used to evaluate the new design method.

Part of the Working Group's approach to developing or adopting new rules for Section I and VIII was to try out different primary load design methods. The current Division 5 primary load design by elastic analysis Service Load approach was included in the comparison, as was the EPP design rules described here. All the reference problems were assumed to have a 
fixed geometry, loading, and a 100,000-hour design life. The comparison was between the maximum allowable pressure.

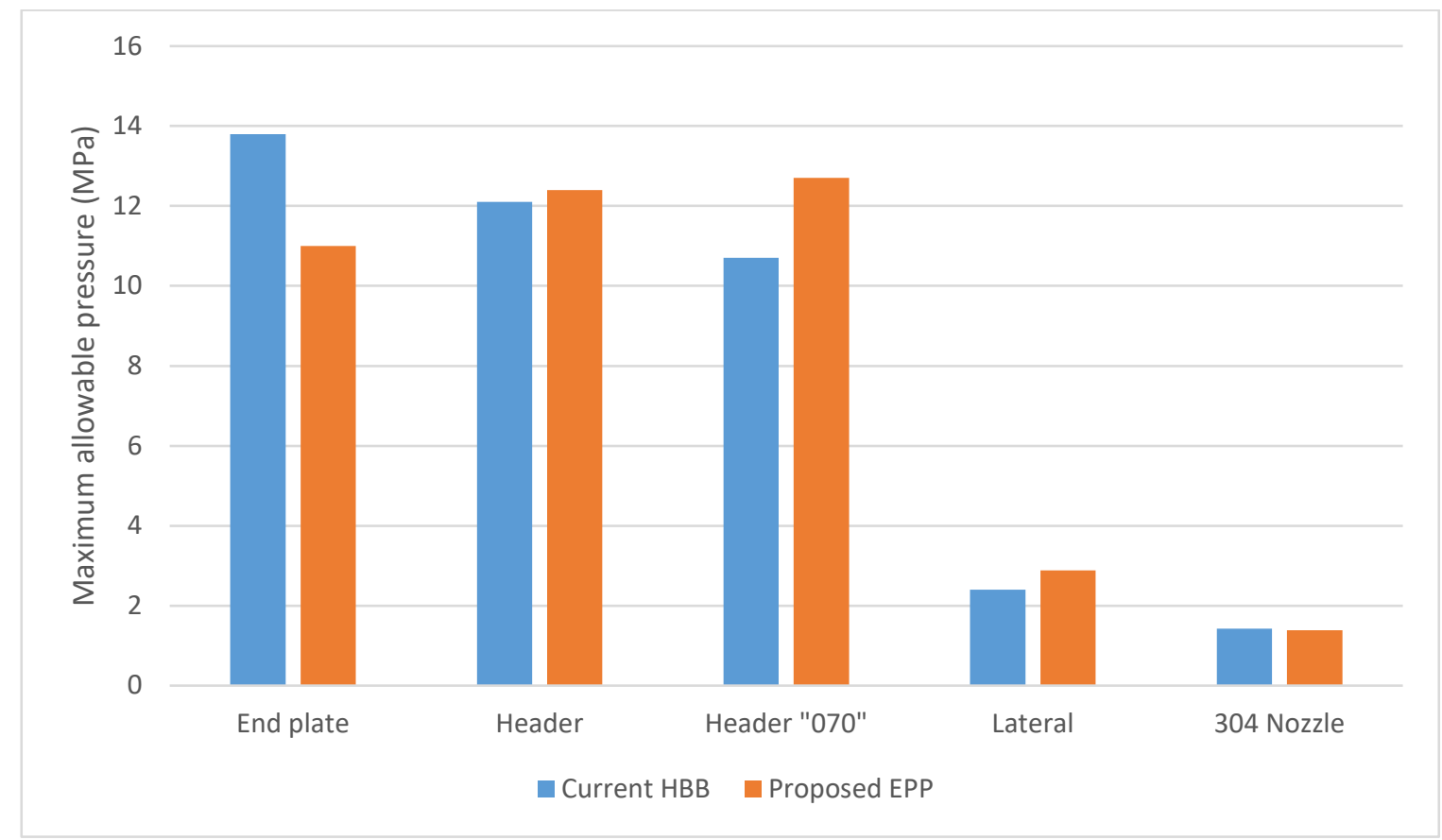

Figure 4.5. Comparison between the current HBB primary load design rules and the new proposed EPP method for the Section I/VIII reference problems.

Table 4.2 lists the outcome of the comparison between the current Division 5 method and the new EPP approach. Figure 4.5 plots the data. Note for the "Current Division 5" results the actual design calculation was carried out with the Code Case 2843 procedures. This Code Case essentially adopts the Division 5 rules for Section VIII use. The result listed for the new method is the lesser of the Global Service and Local Service pressures. In this case, as with the flat head geometry, the Global Service criteria controlled for all the reference problems.

Table 4.2. Maximum allowable pressures for the Section I/VIII sample problems.

$\begin{array}{lllll}\begin{array}{l}\text { End plate } \\ (\mathrm{MPa})\end{array} & \begin{array}{l}\text { Header } \\ (\mathrm{MPa})\end{array} & \begin{array}{l}\text { Header } \\ \text { "070” } \\ (\mathrm{MPa})\end{array} & \begin{array}{l}\text { Lateral } \\ (\mathrm{MPa})\end{array} & \begin{array}{l}304 \text { Nozzle } \\ (\mathrm{MPa})\end{array} \\ 13.8 & 12.1 & 10.7 & 2.40 & 1.43 \\ 11.0 & 12.4 & 12.7 & 2.88 & 1.39\end{array}$

With the exception of the end plate, the allowable pressure for the new design rules slightly exceeds the allowable pressure for the current rules. However, the allowable pressures are within $20 \%$ for all cases and closer to $5 \%$ for most of the problems. The ability of the new EPP rules to redistribute stress throughout the structure accounts for this increase in allowable pressure, which is a reduction in over conservatism compared to the current rules. The EPP allowable pressure for the end plate problem is about $20 \%$ less than for the current rules. 
We suspect this outlier was caused by difficulties in selecting an adequate stress classification line (SCL) in the design by elastic analysis procedure.

As with the flat head problem, in all these example problems the Global Service check controlled over the Local Service check. For adequate geometric designs - except for the nozzle-sphere these are all commercially-design components - we anticipate the Local Service check will not constrain the design. However, it is an important screening test for inadequately designed details causing excessive stress concentration.

This document does not detail the comparison between the Division 5 approaches and the proposed Section I/VIII methods. This comparison is documented in reference [19] as well as in the committee's report. In general, when using similar allowable stresses, all the design approaches tended to produce about the same maximum allowable pressure. However, the Section I and Section VIII allowable stresses are somewhat higher than the Section III, Division 5 time-dependent allowable stress $S_{m t}$ due to differences in the creep criteria going into the definition of the allowable stress. As such, the Section I/VIII methods tend to produce higher allowable pressures.

\subsection{Verification summary}

These examples verify that the new proposed primary load design rules produce comparable, though somewhat less over-conservative, designs when compared to the existing design by elastic analysis primary load design method in HBB. For simple, non-redundant structures, like the cylindrical shell and the beam, the rules produce essentially identical designs. For more complicated, realistic components the new design rules produce somewhat more efficient designs, with higher allowable pressures and/or longer maximum design lives. The ability for the new rules to redistribute stress in a redundant component produces this increased efficiency, which lessens the over-conservatism inherent in a design by elastic analysis approach for problems with substantial inelasticity.

The final set of examples, the Section I/VIII reference problems, present a strong case for the new design method. For these problems the EPP method produces very similar, if slightly more efficient, designs than the current HBB rules. These geometries are the most representative evaluated here, as many are commercial Section I or Section VIII designs that saw actual service in operating plants. The fact that the new design rules and old HBB rules produce similar designs for these representative components verifies that the new proposed rules will produce safe, efficient primary load designs. 



\section{Conclusions}

This report develops a new set of primary load design criteria suitable for the design of high temperature, Class A nuclear components like core blocks and complicated heat exchangers. The rules eliminate the requirement of stress classification and are compatible with modern finite element analysis but still retain the current Code allowable stresses and material data. The rules are validated by comparison to designs using the current HBB design-by-elastic analysis approach.

Overall, the new rules greatly simplify the primary load design process, particularly for engineers trained on modern FEA software. Additionally, the elimination of stress classification means the rules are likely more accurate than the current approach for components with complicated geometries. Finally, adopting simple inelastic analysis through EPP and elasticcreep constitutive models allows the new design approach to fully account for load redistribution due to creep and plasticity, meaning the new design rules produce something less restrictive structures than the current HBB approach using elastic stress analysis.

The next step will be to present the design rules to the relevant ASME Code Committees for adoption as a nuclear Code Case. This process will begin shortly after the completion of this report with a ballot in the BPV III Working Group on Analysis Methods. We anticipate that the rules could be adopted in three or four balloting cycles, meaning the Code Case could be available for design use sometime in 2021. 



\section{ACKNOWLEDGEMENTS}

The research was sponsored by the U.S. Department of Energy, under Contract No.

DEAC02-06CH11357 with Argonne National Laboratory, managed and operated by UChicago Argonne LLC. Programmatic direction was provided by the Office of Nuclear Reactor Deployment of the Office of Nuclear Energy. The authors gratefully acknowledge the support provided by Sue Lesica, Federal Manager, Advanced Materials, Advanced Reactor Technologies Program, Tom Sowinski, Federal Manager, Microreactor Program, and Jess C. Gehin of Idaho National Laboratory, National Technical Director, Microreactor Program.

The authors thank Peter Carter of Stress Engineering Services for helpful discussions, particularly on the development of the equilibrium field scaling approach and on the development of the effective stress measure. The authors further thank the members of the joint Section I/Section VIII Working Group on Elevated Temperature Design for supplying some of the reference problems used in Chapter 4. 



\section{REFERENCES}

[1] P. Carter, R. I. Jetter, and T.-L. Sham, "Application of elastic-perfectly plastic cyclic analysis to assessment of creep strain," in Proceedings of the ASME 2012 Pressure Vessels \& Piping Division Conference, PVP2012-78082, 2012.

[2] P. Carter, R. I. Jetter, and T.-L. Sham, “Application of shakedown analysis to evaluation of creep-fatigue limits," in Proceedings of the ASME 2012 Pressure Vessels and Piping Division Conference, PVP2012-78083, 2012.

[3] J. Lubliner, Plasticity Theory. Mineola, New York: Dover Publications, 2008.

[4] L. D. Blackburn, "Isochronous Stress-Strain Curves for Austenitic Stainless Steels," in The Generation of Isochronous Stress-Strain Curves, A. O. Schaefer, Ed. The American Socieity of Mechanical Engineers, 1972, pp. 15-48.

[5] A. B. Smith, "Revised Incoloy 800H Isochronous Stress Strain Curves for Code Case 1592,” 1976.

[6] M. C. Messner, R. I. Jetter, and T.-L. Sham, “A High Temperature Primary Load Design Method Based on Elastic Perfectly-Plastic and Simplified Inelastic Analysis,” in Proceedings of the ASME 2020 Pressure Vessels and Piping Conference, 2020, pp. PVP2020-21470.

[7] R. L. Klueh and T. L. Hebble, "A Mathematical Description for the Stress Strain Behavior of Annealed 2-1/4 Cr-1 Mo Steel,” J. Press. Vessel Technol., vol. 96, no. 2, pp. 118-125, 1976.

[8] M. K. Booker, “Analytical Description Of The Effects Of Melting Practice And Heat Treatment On The Creep Properties Of 2 1/4 Cr-1 Mo Steel,” in Effects of Melting and Processing Variables on the Mechanical Properties of Steel, G. V. Smith, Ed. American Society of Mechanical Engineers, 1977, pp. 1-44.

[9] R. W. Swindeman, “Construction of Isochronous Stress-Strain Curves for 9Cr-1Mo-V Steel,” Publ. Am. Soc. Mech. Eng. Press. Vessel. Pip. Div., vol. 391, pp. 95-100, 1999.

[10] M. C. Messner and T.-L. Sham, “Isochronous stress-strain curves for Alloy 617,” in Proceedings of the 2019 ASME Pressure Vessels and Piping Conference, PVP2019-93642 2019.

[11] F. A. Leckie and D. R. Hayhurst, “Constitutive equations for creep rupture,” Acta Metall., vol. 25, no. 9, pp. 1059-1070, 1977.

[12] D. R. Hayhurst, “Creep of metals under multi-axial states of stress,” J. Mech. Phys. Solids, vol. 20, pp. 381-390, 1972.

[13] R. L. Huddleston, “An Improved Multiaxial Creep-Rupture Strength Criterion,” J. Press. Vessel Technol., vol. 107, no. November, pp. 421-429, 1985.

[14] R. L. Huddleston, “Assessment of an improved multiaxial strength theory based on creeprupture data for type 316 stainless steel,” J. Press. Vessel Technol., vol. 115, no. 2, pp. 177-184, 1993. 
[15] R. L. Huddleston, “Two-Parameter Failure Model Improves Time- Independent and TimeDependent Failure Predictions,” Technical report, Lawrence Livermore National Laboratory, UCRL-TR-202300, 2003.

[16] O. Nassif et al., "Combined crystal plasticity and grain boundary modeling of creep in ferritic-martensitic steels: I. Theory and implementation,” Model. Simul. Mater. Sci. Eng., vol. 27, no. 7, 2019.

[17] M. C. Messner et al., "Combined crystal plasticity and grain boundary modeling of creep in ferritic-martensitic steels: II. The effect of stress and temperature on engineering and microstructural properties,” Model. Simul. Mater. Sci. Eng., vol. 27, p. 075010, 2019.

[18] M. H. Jawad and R. I. Jetter, Design and Analysis of ASME Boiler and Pressure Vessel Components in the Creep Range. ASME Press, 2009.

[19] D. Dewees, R. Nadarajah, B. Hantz, J. A. Mann III, M. Messner, and D. Anderson, "Comparison of Candidate Steady Loading Elevated Temperature Design-by-Analysis Methods," Submitted for publication, 2020. 



\section{Argonne}

\section{Applied Materials Division}

Argonne National Laboratory

9700 South Cass Avenue, Bldg. 212

Argonne, IL 60439

www.anl.gov

Argonne National Laboratory is a U.S. Department of Energy laboratory managed by UChicago Argonne, LLC 